\title{
The development, implementation and evaluation of a system based physical activity promotion program in a free, rural, primary care clinic
}

\author{
Martha E. Summers \\ West Virginia University
}

Follow this and additional works at: https://researchrepository.wvu.edu/etd

\section{Recommended Citation}

Summers, Martha E., "The development, implementation and evaluation of a system based physical activity promotion program in a free, rural, primary care clinic" (2009). Graduate Theses, Dissertations, and Problem Reports. 2935.

https://researchrepository.wvu.edu/etd/2935

This Dissertation is protected by copyright and/or related rights. It has been brought to you by the The Research Repository @ WVU with permission from the rights-holder(s). You are free to use this Dissertation in any way that is permitted by the copyright and related rights legislation that applies to your use. For other uses you must obtain permission from the rights-holder(s) directly, unless additional rights are indicated by a Creative Commons license in the record and/ or on the work itself. This Dissertation has been accepted for inclusion in WVU Graduate Theses, Dissertations, and Problem Reports collection by an authorized administrator of The Research Repository @ WVU.

For more information, please contact researchrepository@mail.wvu.edu. 
The Development, Implementation and Evaluation of a System Based Physical Activity Promotion Program in a Free, Rural, Primary Care Clinic

Martha E. Summers, MSN, FNP-BC

\author{
Doctoral Research Project submitted to the \\ School of Nursing \\ at West Virginia University \\ in partial fulfillment of the requirements for the degree of \\ Doctor of Nursing Practice \\ Susan McCrone, Ph.D., Chair \\ Lisa Hardman, D.N.P. \\ Bill Reger-Nash, Ed.D
}

Morgantown, West Virginia

2009

Keywords: physical activity, primary care providers, underserved, low-income, rural patients 


\section{ABSTRACT}

The Development, Implementation and Evaluation of a System Based Physical Activity Promotion Program in a Free, Rural, Primary Care Clinic

Martha E. Summers

\section{Background}

Despite the consequences of physical inactivity, it is under recognized and not addressed consistently in primary care. The Healthy People 2010 recommendations are that adults should engage in at least 30 minutes of moderate physical activity on most, preferably all, days of the week. Clinical practice guidelines advise that primary care practitioners take the opportunity whenever possible to advise, discuss, negotiate, or encourage physical activity in inactive adults.

\section{Objective}

The primary objective was to identify beliefs about physical activity that act as barriers among providers and to educate them about the current recommendations for physical activity. An additional objective was for providers to increase the frequency of the discussion of physical activity and establish a plan with patients as documented in the charts.

\section{Subjects}

The participants were seven health care providers (six nurse practitioners and one physician's assistant), at one free clinic, serving a primarily, rural, female, low income population.

\section{Methods}

A 30 minute educational program was conducted with the providers that included the latest recommendations for physical activity. Two surveys, one on attitudes and beliefs, and one on knowledge were given at three time points: prior to and immediately after the education, and after the twelve week intervention. A reminder in the form of a worksheet incorporating the 5 A's of behavioral change was developed as a tool for the providers to use. Patient charts were reviewed three months prior to and three months after the intervention to assess the frequency of discussions about physical activity.

Results

There was a statistically significant increase in knowledge and a significant change in attitude after the education program. There was also a significant increase in the documentation of a discussion of physical activity and inclusion of a plan to increase exercise in the twelve week period after the education session.

\section{Discussion}

The use of a brief, one session educational program resulted in significant increases in knowledge and change in attitudes that were sustained over a twelve week period. This increase in knowledge and the use of paper prompts increased the assessment and development of plans to increase activity in a very sedentary, low income, rural primary care clinic population. Future plans include the inclusion of an electronic prompt in the electronic charts to encourage sustainability of the program. 


\section{ACKNOWLEDGEMENTS}

Sincere appreciation is extended to my committee chair, Dr. Susan McCrone for her persistent guidance and scholarly expertise. I would like to thank Dr. Lisa Hardman for her caring and gentle presence. Thank you to committee member, Dr. Bill Reger-Nash for serving as the content expert for this project. I am fortunate to be associated with all of the committee members.

I would like to recognize my family and friends for their untiring support throughout this endeavor. Finally, I would like to dedicate this work to the memory of my mother. Her unselfish support, encouragement, and belief in my ability to succeed will live in my heart forever. 


\section{Table of Contents}

Background and Significance of Problem ......................................................................... 1

Theoretical Framework................................................................................................... 5

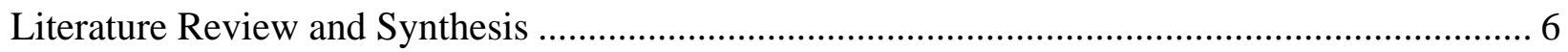

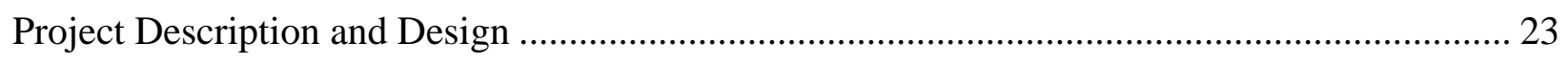

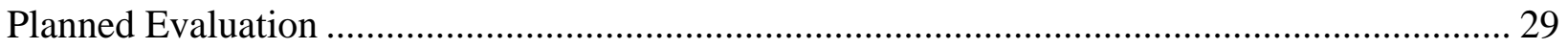

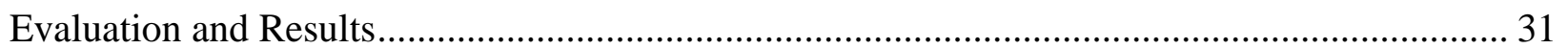

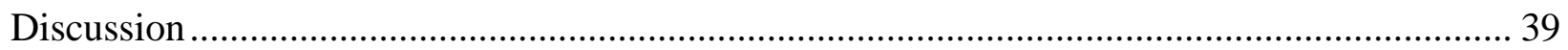

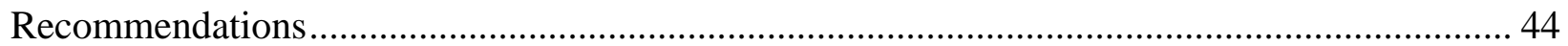

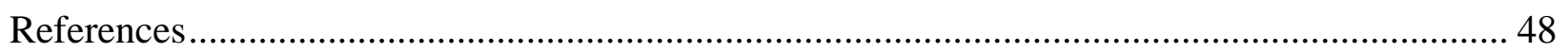

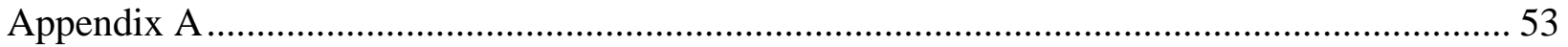

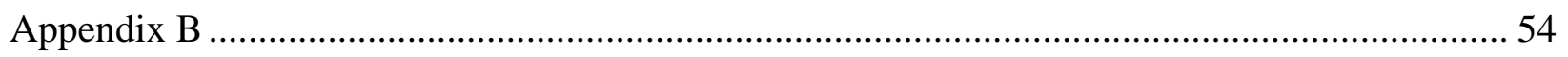

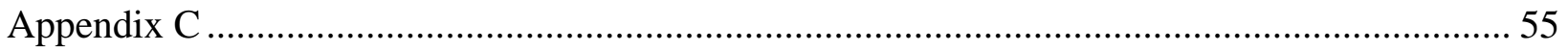

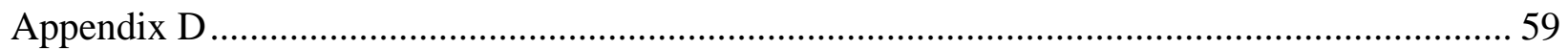

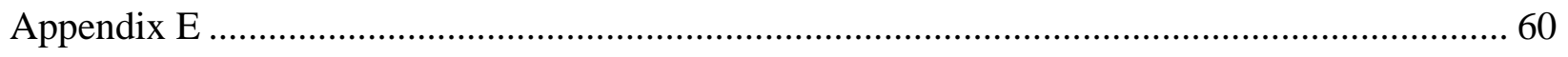

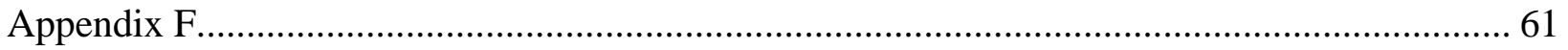

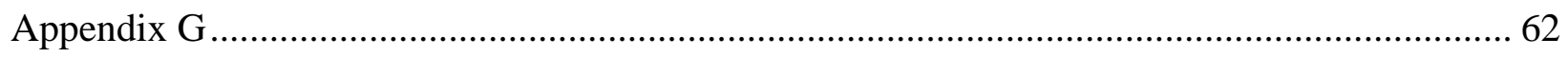


Background and Significance of Problem

\section{Problem Statement}

Inactivity, a health concern resulting in overweight, obesity, diabetes, and cardiovascular disease, is under recognized and under addressed in primary care (Schrop, et al., 2006). People in general are not getting enough exercise and expending less energy than they consume (WHO, 2003). Additionally, large shifts towards less physically demanding work have been observed worldwide, and less physical activity is found with the increasing use of automated transport, technology in the home and workplace, and more passive leisure pursuits (WHO, 2003). Since physical demands in both work and activities of living have decreased with technological advances, it is necessary to intentionally increase levels of activity.

Americans in low socioeconomic groups show higher rates of mortality and suffer disproportionately from almost every disease (Schrop, et al., 2006). Low-income and rural adults are less likely to exercise at recommended levels than others. Some of the barriers for low socioeconomic groups are poor health, lack of time, feeling too tired, and limited access to walking trails, parks, and malls (Burton, Turrell, \& Oldenburg, 2003). This aptly describes the population chosen for this project at Milan Puskar Health Right (MPHR). In order to qualify for services at MPHR, patients must meet the income criteria determined by the national poverty guidelines. These guidelines are published yearly. Patients seen at MPHR are generally uninsured or underinsured. Many work in low paying minimum wage jobs and are unable to afford health care. In many instances, the patients are the working poor.

The national rate of physician counseling about exercise was found to be approximately 34\% (Schrop, et al., 2006). Studies have shown that providers are more likely to counsel patients 
with cardiovascular disease and diabetes than those who are relatively healthy but sedentary. Low income patients in need of these discussions were less likely to be counseled than their high income counterparts (Schrop, et al.). The problem indentified within MPHR is that there is no consistent method in place to address the issue of physical activity with patients. Because of the sometimes chronic and large numbers of health concerns with which patients are being treated in this setting, health promotion topics are not necessarily in the forefront of the provider's approach to care.

Clinical practice guidelines advise that primary care practitioners take the opportunity whenever possible to advise, discuss, negotiate, or encourage physical activity in inactive adults (National Institute for Health and Clinical Excellence (NICE), 2006). The MPHR clinic does not have a consistent method in place to address the issue of physical activity with patients. Many diagnoses in a low income and rural population can be prevented or ameliorated by lifestyle interventions that include physical activity. Commonly encountered diagnoses in the patients at MPHR include: hypertension, dyslipidemia, diabetes, hypothyroidism, cardiovascular disease, depression, and anxiety.

\section{The Impact of Rurality in West Virginia}

West Virginia is the second most rural state in the nation and is the only state falling completely within the region known as Appalachia. Sixty-four percent of the state's population lives in communities of fewer than 2,500 people. Forty-five of West Virginia's 55 counties are designated as rural (WVDHHR, 2005). Fifty counties are wholly or partially designated as medically underserved areas (WVBPH, 2001). Almost one-fifth (18.9\%) of West Virginia adults age 18-64 had no health care coverage in 2006 (BRFSS, 2006).West Virginia has the highest disability rates of any state in the nation. More than $26.4 \%$ or 410,781 persons are disabled 
because of a physical, mental, or emotional problem (BRFSS, 2006). This number includes children age five and above. It is likely that the disability rates are influenced by the disproportionate number of West Virginians with arthritis. According to the BRFSS 2006 report, West Virginia ranked higher than any other state in the prevalence of adults with some form of an arthritis diagnosis. More than four in ten adults with arthritis symptoms (43.5\% in 2006) also reported some related limitations in their usual activities (BRFSS, 2006). Disabilities can potentially create additional barriers to disease prevention and decrease participation in health promotion activities such as exercise or walking.

West Virginia's nickname, the Mountain State, is well deserved with the mean elevation being 1,500 feet above sea level (WV NETSTATE, 2008). Some of the most rugged land in the country can be found in this state. Long distances to medical facilities and poor rural road conditions are among the barriers to those seeking health care (Coyne, Demian-Popescu, \& Friend, 2006). According to a national healthcare disparities report, rural residents when compared with their urban counterparts are more likely to be elderly, poor, in fair or poor health, to have chronic conditions, and to die from heart disease (AHRQ, 2005). This aptly describes West Virginia with the second highest percentage of older residents in the United States and a high prevalence of diabetes and heart disease.

\section{Physical Activity}

Physical inactivity is recognized as a major threat to public health in the United States and combined with poor nutrition is estimated to cause $16 \%$ of deaths and approximately 24.4 billion dollars per year in health care expenditures (Mokdad, Marks, Stroup, \& Gerberding, et al, 2005; Colditz, 1999). Healthy People 2010 recommends that adults should engage in at least 30 minutes of moderate physical activity on most, preferably all, days of the week. Further, it is 
recommended that the proportion of adults who regularly participate in moderate or vigorous activity, increase to at least $50 \%$. However, more than $60 \%$ of U.S. adults do not achieve this amount and are by definition insufficiently active (U.S. Department of Health and Human Services, 2000). The reduction in physical activity in this country has contributed to the obesity epidemic. According to the World Health Organization (WHO, 2003), obesity has reached epidemic proportions globally and is a major contributor to the global burden of chronic disease and disability. It is estimated that more than 1 billion adults are overweight and at least 300 million are clinically obese (WHO). As of 2007, 63\% of the United States’ population was overweight, with $26.3 \%$ designated as obese (BRFSS, 2006). Furthermore, increased consumption of more energy-dense and nutrient poor foods combined with reduced physical activity have led to obesity rates that have risen three-fold, or more since 1980 in some areas of North America, the United Kingdom, Eastern Europe, the Middle East, and the Pacific Islands (WHO, 2005).

Among the challenges of this change project is designing a patient-focused, physical activity, education system that is convenient for providers to use. The primary investigator held conversations with several of the six regular providers at MPHR and two formal meetings took place with the director of the clinic to gain permission to implement the project. An additional meeting was conducted with the director of clinic services, a registered nurse. The literature was reviewed at many different intervals during the planning process in an attempt to locate studies and similar projects to assist in narrowing the focus. The literature was further reviewed to assess the most practical method to implement the change without imposing additional organizational and provider strain. 
Opportunities leading to the project included an informal verbal assessment of the providers indicating that many were interested in strategies to implement physical activity interventions. Implementation of this project will provide the staff resources to meet this need. Another opportunity identified is the organizational support from the clinic director. Since the project will be implemented in warmer months, seasonality is right for promoting outdoor activities. For those patients with limited exercise tolerance or for use in the winter months, pamphlets with a variety of practical indoor activities to increase exercise will be provided.

A physically active lifestyle has been associated with health benefits, including improved control of obesity, cardiovascular disease, hypertension, dyslipidemia, arthritis, and reduced overall mortality and morbidity (U.S. Department of Health and Human Services, 2000). Further benefits of physical activity may include: reduction of anxiety, improvement in sleep, prevention and rehabilitation of low back problems, increase in the success of smoking cessation, and the possibility of a role in the prevention of colon and breast cancer (National Guidelines Clearing House, 2006).

\section{Theoretical Framework}

An abbreviated version of Everett Roger's Diffusion of Innovations Theory was used as a guide for the development of this project (Rogers, 2003). This theory has been successful, for example, when used with tobacco policies for smoke free environments. Known simply as Stage Theory, it is based on the idea that organizations pass through a series of steps or stages as they change. These steps or stages are as follows: problem definition (awareness), initiation of action (adoption), implementation, and institutionalization (Rogers, 2003).

In the awareness stage, the problem is recognized and analyzed, and solutions are sought and evaluated. Initiation of action takes place during the second stage or the adoption phase. 
Policies or directives are formulated, and resources for beginning the change are allocated. In the third stage, the implementation of change, innovations are implemented, reactions occur, and role changes occur. The final stage is the institutionalization of change when the policy or program becomes entrenched in the organization. In the last stage, new goals and values are internalized (Rogers, 2003).

This theory falls under the broad category of organizational change. Organizational change is best promoted at multiple levels within an organization. The stages signal when to involve organization members and decision makers at various points in the change process (Rogers, 2003). An example of promoting this project at multiple levels was demonstrated by first introducing the problem and the planned project to the clinic director for discussion and approval. Others at various levels were also verbally contacted about the project. They included: the nurse practitioners, physician’s assistant, nursing staff, social workers, and clerical staff.

The problem was identified through experience in this clinic as a provider, knowledge of current practice guidelines, and through discussions with other providers. The review of the current literature on the topic of physical activity reinforced its importance and aided in establishing awareness of the problem as well. The adoption and implementation will occur when the project is fully put into practice. Institutionalization will take place when the program becomes entrenched in the organization and the providers consistently address the topic with patients. Institutionalization may also occur if the change is eventually incorporated into the new electronic medical record, which has been recently added to the MPHR clinic.

Literature Review and Synthesis

The following literature review is organized according to several topics addressing the issue of physical inactivity. The first section of the literature review includes a discussion about 
declining physical activity. A variety of interventions found in the literature will be discussed as well as provider barriers and attitudes, including the lack of sufficient education and training in primary prevention. Finally, interventions specifically targeting underserved populations will be addressed.

Declining Levels of Physical Activity

Declining levels of physical activity contributes to a number of health problems including: diabetes, coronary artery disease, osteoporosis, and obesity. The health benefits of an active lifestyle have been extensively documented. Traditional approaches to activity counseling and referral need to be broadened to include every day activity, particularly with low-income, obese, marginalized patients where referral to a gym or other exercise facility may not be practical (Wormald, Water, Sleap, Bremer, 2006; Speck, Hines-Martin, Stetson, Looney, 2007).

Benefits of physical activity may include: reduction of anxiety, improvement in sleep, prevention of and rehabilitation of low back problems, increase in the success of smoking cessation, and may help in the prevention of colon and breast cancer (National Guidelines Clearing House, Finnish Medical Society, 2006). Considering the benefits, it seems advisable for primary care practitioners to promote physical activity for the population in general.

A prospective study examining physical fitness and all-cause mortality with a total of 110,482 person-years of observation found that low physical fitness was an important risk factor in both men and women (Blair, et al., 1989). The average years of follow-up in this study was eight years. Age-adjusted all-cause mortality rates declined across physical fitness quintiles from 64.0 per 10,000 person-years to 8.5 per 10,000 person-years. These trends remained after statistical adjustment for age, smoking habit, cholesterol level, systolic blood pressure, fasting blood glucose level, parental history of coronary heart disease, and follow-up interval. The 
authors concluded that higher levels of physical fitness appear to delay all-cause mortality primarily due to lowered rates of cardiovascular disease and cancer (Blair, et al., 1989).

A subsequent report written by Blair and Powell in 1994 estimated the public health burdens of sedentary living habits. It was reported that estimates indicate that sedentary living is responsible for about one-third of deaths due to coronary heart disease, colon cancer, and diabetes; three diseases for which physical inactivity is an established causal factor. Therefore, the authors estimated that presumably if everyone were highly active, the death rate from these three diseases would be only two-thirds of the current rate. However, not everyone will become highly active. So, assuming smaller increases in physical activity practices, the authors suggest that mortality from these three conditions combined could be reduced by as much as 5-6\% or 30,000-35,000 deaths per year with an overall reduced mortality in the United States of about 11.5\%. Blair and Powell proposed that the greatest gains would accrue from strategies that encourage those who report no leisure-time activity to do some, and encourage those who are irregularly active to participate in 30 or more minutes of light to moderate activity for 5 or more days per week. The authors concluded that mortality is only one aspect of public health burdens that would be reduced by greater participation in regular physical activity. Quality of life would also improve (Blair \& Powell, 1994).

\section{Interventions}

The literature identifies that providers agree that the topic of physical activity needs to be addressed with patients, but many struggle with the most efficient and effective methods to do this (Schrop, et al., 2006). Provider intervention has been shown to be an important step for patients in beginning and maintaining a physically active lifestyle (Schrop, et al.) 
Two clinical practice guidelines reviewed were developed by the National Institute for Health and Clinical Excellence (NICE) and evaluated using the AGREE instrument. Initiated by the Department of Health (DH), the task was to produce guidance on four common methods used to increase physical activity-levels. Each of the four methods was searched in the literature. The methods were brief interventions in primary care, exercise referral schemes, pedometers, and community-based exercise programs for walking and cycling. The objectives and clinical questions were specifically described. The guideline was meant to apply to inactive adults and the stakeholder involvement included individuals from all relevant professional groups. Patient views and preferences were not assessed, but the authors recommend assessment of knowledge, attitudes, and skills as outcomes as well as physical activity. There were no pilot studies done using the guidelines. The search methods were described in detail including search terms used and selection criteria. Also, where possible, recommendations were linked to an evidence statement and detailed in the appendices.

The second clinical guideline reviewed "Behavioral Counseling in Primary Care to Promote Physical Activity: Recommendation and Rationale” originated from the 2002 United States Preventive Services Task Force (USPSTF). The objectives were explicitly described as a summary of recommendations on counseling by primary care physicians to promote physical activity and the supporting scientific evidences. This was an update of the 1996 USPSTF recommendations. The development group included individuals from relevant professional disciplines and was sent to 13 outside experts for review. The targeted users and stakeholders were readily identifiable. Details of the databases searched, the terms and limits used were explicit. Balance sheets and expert consensus were used for formulating the recommendations. Successful approaches for implementing prevention included: community involvement, training 
and incentives for clinicians, and the use of information systems. The potential organizational barriers in applying the recommendations were discussed and included: lack of time, no insurance, lack of access to health care, and lack of organized systems in most practices to ensure the delivery of recommended preventive services (USPTF, 2002). No piloting of the guideline was mentioned, but this was an update from a previous guideline and it may not apply.

A quasi-experimental study conducted with women at three rural primary care locations in Missouri studied a simple walking program intervention which provided an exercise video tape, a pedometer, and a daily log (Sherman, Gilliland, Speckman, \& Freund, 2006). Data was collected at four points in time and encouragement to continue was given by the same nurse practitioner at each point. Of the initial 75 participants, 61 completed at least one follow-up encounter. Over the six month study period, participants increased their step counts by a mean of 2573 steps per day. Threats to validity were self-reporting of steps, the relatively small sample size ( $n=61$ ), no control group, and the relatively short duration of the study. Additionally, the findings may not be generalizable to men or urban populations. Strengths were that one nurse practitioner did all of the follow-up allowing for internal validity. Analyses were adjusted for those that did not complete the study.

A randomized controlled trial with 719 participants studied the use of a wide spread, print, media intervention to promote physical activity in a statewide population (Marshall, Bauman, Owen, Booth, Crawford, \& Marcus, 2004). Stages of readiness to become physically active were assessed at baseline and the experimental group was sent stage-targeted booklets and a personalized letter. Data were collected via telephone at baseline, two, and eight months. At two months, the mean total activity increase in the intervention group was $13 \mathrm{~min} /$ week but decreased by $14 \mathrm{~min} /$ week in the control group. At eight months, the intervention group 
maintained the increase, but the control group reported a $15 \mathrm{~min} /$ week increase from baseline. The changes in mean physical activity levels were not statistically significant. Strengths were the large sample size, a control group, interviewers that were blinded to group allocation, and a tool that had been previously piloted. External validity was strengthened by the high retention rate as well. The use of self-report potentially threatens validity as it may introduce the issue of social desirability and relies on retrospective recall, which may be a source of bias. The authors noted another possible confounding variable was the differences in climates between the two studies, one being coastal and the other statewide. Diversity was considered a strength and a limitation, as the sample was representative of the state's entire population in terms of the sociodemographic profile.

The focus of one meta-analysis was to assess the effects of interventions for promoting physical activity in adults 16 years and older not living in an institution (Hillsdon, Foster \& Thorogood, 2005). The appraisal tool used was the SIGN checklist for meta-analyses. The authors studied only randomized controlled trials using a systematic approach and the same criterion for each review. Any disagreement was discussed with an additional reviewer and resolved by consensus. The heterogeneity in reported effects was reduced in higher quality studies, when physical activity was self-directed with some professional guidance and when there was on-going professional support. The authors reported that because of the clinical and statistical heterogeneity of the studies, only limited conclusions could be drawn about the effectiveness of individual components of the interventions. The authors' review suggested that physical activity interventions have a moderate effect on self-reported physical activity and cardio-respiratory fitness, but not on achieving a predetermined level of physical activity. It was determined that future analyses should provide details of the interventions. 
Three studies, two quasi-experimental, and one randomized controlled trial all reported that social support, either from family, friends, focus group members, or health care providers had an impact on increasing physical activity in inactive adults (Speck, Hines-Martin, Stetson, \& Looney, 2007; Marcus, et al., 2007; Sherman, Gilliland, Speckman, \& Freund, 2007). The studies that relied on self-reporting of physical activity cited potential problems with internal validity. Only one study had a truly objective measure of physical activity, using a computerized program in an exercise facility (Shepich, Slowiak, \& Keniston, 2007). In this study, Shepich et al concluded that full subsidization and third party monitoring increased exercise rates (Shepich, 2007). Of course, this is not applicable across all populations, especially in the uninsured.

The effects of a mailed, “no-contact”, self-help, walking program, with and without a pedometer on walking behavior was compared to a "no-treatment” control group in a community sample of inactive adults (Merem, Rissel, Phongsavan, Smith, Van Kemenade, Brown, \& Bauman, 2007). The authors also examined whether intervention effects were carried over to other forms of physical activity. The experimental group significantly increased participation in other sports/recreation and was more likely than the control group to meet physical activity recommendations. Strengths of the study were that interviewers were blinded to group allocation and participants were not aware that there were two types of interventions. A weakness noted was that the sample was $85 \%$ women, $92.9 \%$ English speaking, and a large percentage were college educated (45.5\%). Therefore, the results may not be generalizable to men or less educated individuals.

Two-hundred and sixty-five subjects at 24 Finnish health care sites participated in a randomized controlled trial that examined the effectiveness of prescription-based counseling and self-monitoring in the promotion of physical activity in primary health care (Aittasalo, 
Miilunpalo, Kukkonen-Harjula \& Pasanen, 2006). Patients were randomized to a prescription (PREX) or a non-prescription group and assigned to their groups according to their physicians. The prescription group included physician counseling about physical activity. Every other patient of the non-prescription physicians received a pedometer, a physical activity log, and feedback about their log recordings. The remainder served as controls and received usual care. At two months, the mean increase in weekly overall physical activity was 1.0 (95\% CI 0.1 to 1.5 ) session more in the prescription group. At six months, physical activity sessions remained higher for the prescription group. In comparison to the controls, self-monitoring increased weekly duration of overall physical activity at 2 months on average by 217 minutes. Potential confounding variables were: variations in physician's counseling approaches, patient's intention to change habits, and patient self-report of activity sessions.

Marcus, Lewis, Williams, Dunsiger, Jakicic, Whiteley, et al. (2007) compared physical activity interventions delivered via print or through the internet. Healthy, sedentary $(\leq 90$ minutes of physical activity each week) men and women were randomized to one of three interventions: (1) motivationally tailored internet ( $n=81)$, (2) motivationally tailored print ( $n=86)$, and (3) 6 researcher-selected Web sites available to the public (standard internet, $n=82$ ). At six months, the tailored internet arm reported 120 minutes, the print arm 112.5 minutes, and the standard internet arm 90 minutes of physical activity per week. At 12 months, the minutes per week were 90, 90, and 80 for those in the print arm, tailored Internet, and standard internet arms, respectively ( $p=.74)$. This represents no significant differences between the three arms. External validity included no differential drop-out rate between groups. Internal validity was strengthened by no significant difference between the three study arms on the demographic and baseline variables. This study, although large, may not be generalizable to the general public as a 
high percentage of the study groups were in higher income brackets, $72.1 \%$ were college educated, and 83.7\% were women (Marcus et al., 2007).

A quasi-experimental, pretest, posttest, cohort study tested an intervention aimed at reducing community environmental barriers to physical activity in low-income women (Speck, Hines-Martin, Stetson, \& Looney, 2007). The intervention group received site based social support from a nurse practitioner, friends, and a safe, accessible, physical environment at the community center. Although there were no between group differences found for physical activity behavior, there was a mean total reduction in cholesterol levels $(p=.007)$ and an increase in the perception of benefits of physical activity $(p=.003)$. The intervention group perceived greater improvement in benefits and a decrease in perceived barriers and a greater increase in social support and self-efficacy. Qualitative data enriching the quantitative data was recorded and then transcribed verbatim to strengthen validity. Again, a threat to validity in this study as in other studies was the use of self-reporting to measure physical activity. Other more objective measures were used such as cholesterol levels, but it would be impossible to say the results were influenced by activity alone.

In a 2006 study, Shepich, Slowiak, \& Keniston determined whether removing cost barriers would enhance participation in exercise programs. The authors focused on cost because it could be addressed experimentally and subsidization (insurance) is an acceptable way to help with medical expenses. They also assessed whether monitoring would promote participation in exercise programs, and particularly whether self-monitoring would enhance subsidization's effect. The results showed that subjects that received reimbursement for the full cost of the gymnasium fee exercised more than those that received half the cost. Those monitored by a third party exercised more than those who monitored themselves. None of the effects obtained for the 
self-recorded exercise rates were significant except for a 12-week decline in the women. Men attended the exercise sessions more than women (mean $=22.82$ vs. 17.15 times, respectively). A computer monitoring system recorded exercise participation. Internal validity was enhanced with power analyses to determine adequate sample size. Using 11 sites contributed to the external validity of the study. This study may be generalizable to other large cities. Again, self-reporting threatens internal validity, but this study had the advantage of a computerized method to monitor physical activity participation at all sessions.

A variety of physical activity interventions have been studied in the literature, including the use of print materials, the internet, group and individual support, subsidization, and others, yet consensus is lacking about any one best intervention and the results are inconclusive. A combination of interventions may prove the most effective. It appears that no single standardized method is agreed upon to assist health care providers to incorporate physical activity education and guidance as part of routine clinic visits.

\section{Underserved Populations}

A study examining the effect of teaching modules on underserved clients' perceived health found that often the underserved are reluctant to seek health care, which results in fewer preventive services (Kessler \& Alverson, 2007). This descriptive study examined the effects of preferred teaching modules on perceived health in a nurse managed center. The majority of participants were female with a high school education $(n=101)$. The authors report that being medically underserved and uninsured can leave individuals living a fine line between wellness and illness and that this population, being selective in their use of health services, often waits until a crisis occurs. Health education, an integral part of holistic care, should include the development of educational materials designed to meet clients' expressed concerns. The authors 
found that individuals who are underserved express a desire to learn about health and to limit barriers to health promotion. Use of various teaching modules was positively correlated with perceived improved health $(p<.05)$. Participants who used a combination of videos and pamphlets reported the greatest improvement $(p<.000)$. The findings from the study indicate the need to include both visual and auditory health education initiatives, and that future research should focus on how to increase other underserved and uninsured clients' use of health education materials (Kessler \& Alverson, 2007). The study should be analyzed considering its limitations. Generalizability was limited related to the small, convenience sampling. Self-report measures have limitations such as lacking objectivity, over reporting of practices, and social desirability. Another limitation was that some items on the survey were left unanswered (Kessler \& Alverson, 2007).

A study published in 2008 examined clinician and patient communication about physical activity in an underserved population (Carroll, et al., 2008). This was a cross sectional, observational study of clinicians and their patients at two urban community health centers in New York State. The center provided primary care to a diverse population of primarily lowincome patients. The main purpose of the study was to observe communication about health in practice. The researchers were examining the actual language used when communicating about physical activity and analyzing the language according to the 5A's guidelines (assess, advise, agree, assist, arrange). The authors suggest that gaps exist in knowledge of the communication about physical activity with underserved populations, not only because providers lack realistic examples of specific communication techniques, but may not fully understand the extent to which competing demands might influence discussion with underserved clients about physical activity. The results of this study revealed that when providers addressed physical activity, their 
efforts were focused on two A's (asking and advising) with little use of agreement, assistance, or arrangements to help with follow through for patients. The authors believe that the barriers of time-pressured environments, competing priorities, systems barriers, and limited resources are magnified for those working with underserved populations. The authors suggest that the last 2 A's, assist and arrange, may be better achieved by collaboration with allied health educators, community programs, or other health care staff resources, given the competing demands that primary care clinicians face. Interestingly, only one discussion about physical activity was initiated by a patient. Therefore, the authors recommend not only that clinicians be educated about practical tools to assist with health promotion, but that underserved patients be taught to activate or prompt the discussion of physical activity (Carroll, et al., 2008).

\section{Barriers and Attitudes}

Certain studies have addressed health care provider's attitudes about and perceived barriers to physical activity education with their patients. A 2007 study by Flocke, Crabtree, and Stange found that logistical problems and priorities of a busy practice impede even the most motivated physicians and nurse practitioners from promoting healthy behaviors. In this study, clinician participants were asked to complete a self-reflective questionnaire on the topic of health behavior discussions with patients. The clinicians were asked to record aspects of health behaviors they addressed during a day of outpatient visits. Physicians were then asked to share insights gathered from the experience. They concluded that effective strategies to address this problem should involve a united approach and engage all staff and community partners, not just the clinicians, for health behavior changes to be optimized (Flocke, Crabtree, \& Stange, 2007). Furthermore, the authors reported that, interestingly, although a motivated group, the challenges in translating health promotion into practice outweighed the resources. Certain limitations were 
noted with this study. The clinician participants were attending a conference on the promotion of health behaviors and were selected based on participation in practice based research networks and on having an interest in health promotion. This limits generalizability of the study to other groups. Another limitation noted by the authors was that the analyses were constrained to the data generated as part of the pre-conference reflective exercises. Also noted was that observation of practice processes and in depth interviews with clinicians and other staff might have produced a greater breadth and depth of information about current approaches to health promotion (Flocke, Crabtree, \& Stange, 2007).

A 2004 study conducted by Douglas, Torrance, van Teijlingen, Meloni, and Kerr in the United Kingdom emphasized the role of primary health care providers in addressing the issue of increasing levels of physical inactivity. Primary care staff's knowledge, attitudes, and experiences associated with advising patients about physical activity during routine visits were examined. A cross-sectional survey of family physicians, practice nurses, and health visitors from four health regions was conducted. Three outcomes were measured and included: (1) health professionals’ knowledge of the current physical activity recommendations, (2) practice related to routine physical activity advising, and (3) associated attitudes. In this study with a response rate of $54 \%(n=757)$, the authors found that confidence and enthusiasm for giving advice was high but that knowledge about current recommendations for physical activity was low. Barriers to routine advising were lack of time and resources. Health visitors and practice nurses were more likely than general practitioners to offer routine advice on physical activity.

Recommendations from this study included improving knowledge of current guidelines for physical activity and considering the development of tools to support individual assessment and advice giving to suit individual circumstances (Douglas, et al., 2006). A strength of this study 
was the response rate of 57\%. The authors reported a possible limitation of the very positive responses reflecting the views of the "enthusiasts"; however they believed that their sample was representative based on the demographic characteristics of the general practitioner respondents compared to the national picture. An additional strength is that compared to other studies, this one asked respondents about their current knowledge and beliefs about current physical activity recommendations. The authors report this as a strength that would have a bearing on whether staff would intervene with advice or not and the nature of the advice given. This study was based on self-reported behavior. The authors recommended that future studies might benefit from the inclusion of observational methods to validate claims of practice (Douglas, et al., 2006).

Reeve, Byrd, \& Quill (2004) conducted a descriptive cross-sectional survey to examine the health promotion attitudes and practices of nurse practitioners in Texas. Although found to have positive attitudes toward health promotion, the findings indicated that improvement was needed in the adoption of certain health promotion practices. The study was conducted via mailed surveys. Of the 727 questionnaires mailed, 446 were returned, leading to a return rate of 64.1\%. More than 98\% agreed that routine screening for obesity, alcohol consumption, and physical inactivity should be included in the history and physical, but only $61 \%$ of respondents agreed that providing these screenings would be easy. The Texas nurse practitioners had very positive attitudes about health promotion, but the attitudes appear to be more positive than the reported practices suggest. The nurse practitioners were asked to identify barriers to the provision of health promotion for every patient seen in practice. The most significant barrier identified (56.9\%) was lack of time. Lack of reimbursement for health promotion was identified as a barrier by $30.8 \%$ of the respondents. Among other barriers noted were: language barriers, lack of patient desire to change and denial of risk, lack of awareness of guidelines, and lack of 
preparation for counseling (Reeve, Byrd, \& Quill, 2004). Reported limitations included those of a self-administered questionnaire and data that is collected via the mail can only approximate actual practices. The response rate of $61 \%$ in this survey is adequate for a mail survey, but nearly $40 \%$ of the N.P.s in the sample did not respond. The authors reported that the generalizability of the study might be hindered by the response rate. There could be those in the group that did not respond that actually put health promotion activities into practice at a greater level than the respondents did. Conversely, those N.P.s that did respond might be more committed to health promotion for patients than those who did not respond. Another limitation is that the sampling of Texas N.P.s may not be representative of the entire country. According to the authors, factors such as social desirability and acquiescence are potential problems in self-report measures and the possibility exists that the N.P.s may have over reported their own screening practices (Reeve, Byrd, \& Quill, 2004).

It may be that another barrier has been created by a lack of sufficient training and emphasis on primary prevention in the education of health care providers. Ducatman, et al. (2005) discussed the status of residency training in preventive medicine. It was found that funding for preventive medicine training was inadequate. The authors, in their discussion of the recent literature, found topics contributing to the ongoing malaise in the specialty of preventive medicine that included: clinical creditability, market demand and compensation for preventive medicine services, career opportunities for preventive medicine clinicians, federal support for training, and public awareness of the contributions of preventive medicine physicians. They concluded that when the public and the federal government see the added value of training in preventive medicine and when rigor is enforced in the various programs, then funding will also increase (Ducatman, et al., 2005). This was not intended to be a scientific study, but rather a 
group of senior leadership members of the Accreditation for Graduate Medical Education (ACGME) and the Residency Review Committee in preventive medicine and invited guests came together to examine preventive medicine training and the relationship of training to the future of the specialty. The only possible limitation is that there was bias because the individuals targeted are those interested in preventive medicine training and that believe the specialty is declining.

Bellas, Asch, \& Wilkes (2000) surveyed first-year medical students at five different schools in California to measure predictors of positive attitudes toward health promotion and prevention. They report that students enter medical school with specific beliefs and values that may affect their practice and may direct what they learn. The response rate was 95\% representing 599 completed surveys. Overall, first-year medical students had moderately positive attitudes toward health promotion and prevention. In their discussion, the authors recommended that in designing curriculum to improve attitudes towards health promotion, medical educators need to consider personal and social values held by students and address the political aspects of health promotion and prevention. There was a discussion about the student activism era in the late 1960s when there was a strong interest in the preventive aspects of medicine and the social factors that caused disease. Of the 599 students surveyed in this study, only five planned to pursue a specialty in preventive medicine. Several limitations were reported. One limitation was that the cross-sectional study was conducted early in the medical education process that measured self-reported attitudes and not behaviors or practice. Also, all of the schools surveyed were in the state of California, and the results may not be generalized to other medical schools. Strengths include a large sample size across multiple campuses with an excellent response rate of 95\%. These strengths should have helped to limit selection bias. The authors concluded that 
further study is needed to determine if the positive values about preventive medicine persist and what factors contribute to their being extinguished (Bellas, Asch, \& Wilkes, 2000).

Attitudes and barriers that providers experience have an impact on the delivery of preventive services, including educating and supporting patients about physical activity. The literature supports the revision of and reemphasis on health promotion and prevention in the education of health care providers. In order to provide holistic care, students in health care programs, need to be aware of the issues, whether they are political, economic, or personal values that interfere with the delivery of education on the topic of physical activity. Furthermore, providers working with underserved patients may underestimate the magnification of the barriers they are confronted with in providing care for this population. Increased knowledge and education about the uniqueness of providing for underserved patients will improve and enhance the delivery of care.

Physical inactivity can contribute to or aggravate many chronic diseases and conditions. The underlying reasons for the increase in physical inactivity are multifactorial, including physical, political, economic, and sociocultural variables. Those living in low socioeconomic groups and rural areas suffer disproportionately from diseases directly or indirectly attributed to this problem. Medical schools may need to examine the need to renew an interest in primary care among its students. Recently, the Robert Wood Johnson Foundation launched a commission to improve the health of all Americans. Risa Lavizzo-Mourey, the president and CEO said:

America cannot continue to ignore that millions of people are sicker than they should be and dying far too young. The evidence tells us that whether or not a person gets sick in the first place often has little to do with their health care. A far greater determinant of a 
person's health is the relationship between how we live our lives and the surrounding economic, social and physical environment (Braveman, 2008, no page number).

The decrease in physical activity and its detriment to the overall general health of the population warrants increased attention from individuals, health care providers, educators, community planners, leaders, and policy makers.

\section{Project Description and Design}

\section{Congruence of Project with Mission of the Organization}

The mission of MPHR is to provide health care at no cost to individuals with limited resources. The organization is committed to minimizing barriers to health care and providing quality comprehensive health care to the state's uninsured and working poor families. Promoting health through direct services, education, and advocacy are the primary goals. Educating the providers, staff, and patients about physical activity is in line with these goals, and offers additional resources for the patients. Instituting the proposed program to promote health has a direct impact on the quality of life of its patients, parallels with the goal of patient advocacy, and is part of a comprehensive plan of care.

The relatively high rates of overweight and obesity in people in West Virginia increases their overall risk of chronic medical condition such as diabetes, cardiovascular disease, hypertension, and stroke. Poverty combined with the remote and rural landscape of the state complicates the issue of health access and lessens opportunities for disease prevention and health promotion. Low income and rural patients face greater challenges and are less likely to be counseled about physical activity. It is apparent that this topic is under recognized and under addressed, which warrants increased attention. The inclusion of this change in the system could 
possibly decrease the disease burden and reduce the need for as many prescriptions, potentially saving cost and improving the lives of patients.

\section{Project Objectives}

The primary objective of this project is the implementation and incorporation of a provider practice change to address the topic of physical activity assessment and promotion in adult patients seeking no cost health care at a rural, primary care clinic. A more specific, measurable, and time oriented goal is that providers will utilize the 5 A's (assess, advise, agree, assist, arrange) with at least $30 \%$ of eligible patients by the end of the implementation period. The specific objectives are:

1. To give providers a tool (5 A's) to help increase the assessment of the topic of physical activity with patients.

2. To increase the provider's knowledge and awareness of this problem. This will lead to an increase in the documentation of the topic with patients.

3. Increased knowledge and awareness of the benefits of physical activity will lead to the documentation of a plan and follow-up with patients.

\section{Proposed Plan}

The proposed plan is to incorporate a model of health promotion directed at physical inactivity using the 5 A's approach. The 5 A's stand for, “assess, advise, agree, assist, arrange” and has been used, for example, in smoking cessation programs (Woolf, et al., 2005). According to Woolf, et al., “Addressing health behaviors in primary care involves a familiar sequence of steps: (1) identifying the behavior (s) in question, (2) giving brief advice, (3) setting goals, (4) arranging for more intensive assistance, and (5) ensuring follow-up” (Woolf, et al. 2005, p.20). 
According to Woolf, this sequence of tasks used to address behavior is embodied in the 5 A's. Furthermore, Woolf reports that the effectiveness of clinicians in promoting health behaviors are probably maximized when practices have systems in place to support the entire counseling sequence of the 5 A's.

According to Glasgow, Emont, \& Miller (2006), the 5A's model of behavior change provides a sequence of evidence-based clinician and office practice behaviors (assess, advise, agree, assist, arrange) that can be applied in primary care settings to address a broad range of behaviors and health conditions” (pg. 245). It is the purpose of this project to utilize the 5 A's as a tool to assist providers to address the topic of physical activity on a routine basis.

An example of how the model might work with physical activity is as follows: assess (ask about physical activity and factors affecting change), advise (give a clear, personal message of encouragement to add physical activity), agree (set goals based on individual factors), assist (help identify personal strengths, positive factors in patient's environment to promote the acquisition of skills, confidence and supports for change), and arrange (schedule follow-up).

Before beginning implementation of the project, Institutional Review Board approval will be obtained. The next step in the process is a retrospective review of 100 patient records. The purpose of this review is to assess if and when the topic of physical activity was addressed with patients. A flow sheet will be used to track certain key words found in the provider's notes from a point three months prior to the education session. Terms such as walking, exercise, and activity will be logged. In addition, demographic data such as age, gender, and co-morbid conditions will be documented.

Next, the education and training of all stakeholders will occur. Promotional and educational materials will be presented during an afternoon lunch session, which will take sixty 
minutes. Verbal and written materials will be disseminated and sample posters and pamphlets will be displayed. The education session serves two purposes: (a) understanding about the value of addressing activity with patients, and (b) provision of skills needed to implement the practice change (See Appendix E for complete curriculum outline). Pre and posttests will be given to the providers only (not all stakeholders) as the providers will be directly involved in implementation (Appendix C for pre-posttests assessing basic knowledge and attitudes about physical activity). A second post test will be administered at the completion of the twelve week implementation period to determine knowledge retention and attitude changes.

A bright green sheet of paper and checklist with the 5 A's will be placed in the patient's chart. The paper will serve as a prompt or reminder for the provider to address the topic. Providers will perform a brief assessment to identify if the patient has any contraindications to exercise. If necessary, providers will document in the chart any specific issues that need to be addressed, for example, comments about the discussion or instructions for follow up. Future plans are to incorporate the A's into the new electronic medical record. The checklist will be used for the primary investigator to track the use of the tool as well (See Appendix D for sample checklist).

Posters with walking tips will be placed in the two waiting areas and eight exam rooms to augment the discussion. A variety of physical activity pamphlets will be provided for patients. In the provider's conference area, a poster will be displayed with reminders about the topic and with each of the 5 A's addressed in detail. There will be cues about how to approach each A in the discussion of physical activity. Pedometers with step logs intended to promote the project and enhance the process will be distributed to participants in the initial phase. In addition to the pedometers, 75 bags containing pamphlets with tips for adding activity in practical ways, lip 
gloss, sunscreen, a water bottle, a box of raisins, a granola bar, and sugarless gum will be distributed to patients by the providers. Periodic reviews with providers during the implementation phase of the project will be conducted to obtain feedback.

Once the change project is implemented over twelve weeks, another retrospective record review of 100 charts will occur. The purpose of this second review of the records is to assess once again when and if providers are addressing the topic of physical activity. The data from both reviews will be analyzed and compared.

Timeline (See Appendix A)

As with any project, it is vital to develop a timeline in order to maintain focus and to track the progress of the plan. The timeline has been divided into three phases (Appendix A). The first phase, during April and May, will be devoted to submitting applications for funding from two sources (AANP, and the Dean's capstone support funding). In addition, during this phase, materials will be developed and the project presented to the clinic staff during the noon hour. Prior to phase two (the implementation phase), approval from the capstone committee and the Institutional Review Board must be acquired in order to proceed.

Phase two, or the implementation phase, is planned to occur during the months of September through November. During this time, the project will be implemented. Prior to the implementation, a pre-intervention chart review will be performed on a sampling of 100 charts. The purpose of the pre-intervention chart review is to determine baseline documentation by providers on the topic of physical activity.

Phase three is planned to take place beginning in December and continuing into fall, 2009. This phase involves the second chart review, compilation of data, reporting of results, and evaluation of the project sustainability. The staff of the free clinic will be invited to a noon hour 
presentation for the purpose of reporting the results, gathering feedback, and making plans for sustainability.

The plans for program succession continue to develop. Ideally, change champions will be identified and take responsibility for revisiting the program of change as needed. It is hypothesized that a permanent systems change will occur and that the 5 A's will become part of usual care. The chart stickers and future electronic prompts will enhance the program succession. As new providers and staff are oriented, it is anticipated that the change will be included, and no longer viewed as new, or as a change, but as standard operating procedure.

\section{Resources}

Personnel resources include six nurse practitioners, one physician’s assistant, two licensed practical nurses, and two medical assistants. The role of the three registration personnel will be to attach the green sheets to the charts. Other personnel requirements involve meeting times with the clinic director and the director of clinic services. During the implementation and evaluation phase, meetings will be conducted as necessary. It is anticipated that some of these meetings will be informal and on an individual basis to discuss the process as needed. Funding for promotional items and food served during the education and results presentations is in the form of a grant awarded from the American Academy of Nurse Practitioners and from the Dean’s fund for DNP student projects.

\section{Equipment}

No actual equipment is needed except for a rack for displaying the physical activity pamphlets. The promotional bags and green sheets could be considered equipment and resources. The promotional bags will be kept in an accessible area for providers and restocked as needed until all 75 bags have been distributed. Ten posters (one in each of the eight exam rooms and one 
in each of the two waiting areas) with messages about practical methods to increase daily activity will serve as additional resources.

\section{Budget}

The projected budget is found Table 1. It includes the cost for pamphlets, posters, pedometers, and chart stickers. Funding has been requested from the American Academy of Nurse Practitioners Foundation through grant monies allocated for DNP student projects. Additional funding has been requested from the Dean of the West Virginia University School of Nursing, who has set aside funds to support DNP capstone projects.

\section{Evidence of Key Site Support}

The dialogue about this project began with the clinic director in the fall 2007 semester. Two scheduled meetings with the director have taken place as well as several phone conversations about the planned project. The verbal and written approvals of the clinic director have been confirmed. See letter from Laura Jones, Executive Director of Milan Puskar Health Right (Appendix B).

\section{Planned Evaluation}

According to the Kellogg Logic Model, a practice change is an output (Logic Model Development Guide, 2004). Outputs pertain to practice changes and outcomes address the impact on patients. For example, an output indicator for this project is the change seen in the process or the system as indicated by the provider's incorporation of the 5 A's into practice. To measure this, a retrospective chart review is planned. Another output then that will be measured is the number of promotional bags with pedometers distributed to patients by providers. The distribution of the bags will be documented on the checklist. After the implementation, the remaining bags will be counted and the number subtracted from the original starting number to 
determine how many were distributed overall. Distribution of pamphlets will be followed as well with the use of the checklist (Appendix D).

A sampling of 100 charts selected at random will be reviewed for evidence of specific discussions about physical activity. A period of time, three months prior to the intervention, will be reviewed. A second chart review of 100 randomly selected charts will be completed twelve weeks after the provider education session to determine if a change has occurred in the incorporation of discussion about physical activity.

Two questionnaires will be administered at three time points: prior to the education (pre), immediately after the education session (post 1), and at the end of the twelve week implementation period (post 2). The first questionnaire, adapted from the American College of Sports Medicine (Appendix C), will measure basic knowledge about recommendations and levels of physical activity. It has fourteen questions and will take about fifteen minutes to complete. The second questionnaire about attitudes and beliefs is a fifteen item survey developed by Ruelaz, (2006). The survey was originally developed to determine beliefs and attitudes about the topic of obesity. Permission was granted to adapt the scale for use with the topic of physical activity. Providers will be asked if they strongly agree, agree, neither agree nor disagree, disagree, or strongly disagree with the statements listed in Table 2. The attitudes and beliefs questionnaire takes approximately ten minutes to complete. Additional data collected will be the use of the "green sheets", which is a checklist for the providers containing prompts about the 5 A's.

Pre and post test scores (post 1 and post 2) will be analyzed using a non-parametric, Kruskal-Wallis technique for analysis of variance between groups or ANOVA (Pallant, 2007). This type of analysis is useful with categorical data and with very small samples. Qualitative data 
included by the providers will be assessed for recurrent themes. The chart review will be analyzed using the Pearson Chi-Square technique for a comparison of pre-implementation and post-implementation documentation. Descriptive statistics will be used to explore the demographics, diagnoses, and BMI of the patients whose charts were reviewed. Descriptive statistics will be used to assess frequency of documentation on the topic of physical activity and to compare the number of times the 5 A's were used to discuss physical activity during a specific timeframe of twelve weeks. Documentation of a specific plan for increasing physical activity and plans for follow-up will be assessed as well. Data from the checklist will be tracked to monitor the number of bags that were distributed and if pamphlets were provided.

\section{Evaluation and Results}

The main objective of this project was to increase health care provider's knowledge, awareness, assessment, and treatment of the problem of physical inactivity. A 30 minute educational program was given to the providers, but the total time involved was about 60 minutes to allow for the completion of the surveys and to allow time for questions. The providers were surveyed about their attitudes, beliefs, and knowledge at three time intervals; pre education, post education (post 1), and post twelve week project implementation (post 2). Open ended responses were collected with the final post test. Additional data collected were the use of the green sheet checklist containing prompts about the 5 A's. Other information collected were the number of project promotion bags distributed.

One hundred, randomly selected charts were reviewed for the time period three months prior (January-March) to the project implementation. Additional data collected during the initial chart reviews were: body mass index (BMI), the most common diagnoses, gender, and age. Only the diagnoses documented in the patient's chart in the problem section were counted, and none of 
the acute problems were counted. The most commonly diagnosed problems were included, not the obscure or less common diagnoses (See Appendix E Flow Sheet for Chart Review).

An additional one hundred charts were reviewed for the three months after the time that the project was in the implementation phase (April-June). The purpose of the chart review was to determine the frequency of provider's assessment of physical activity, the use of the 5 A's during the implementation phase, and plans for follow-up on the topic with patients.

\section{Characteristics of the Providers}

The convenience sample consisted of seven regular health care providers (six nurse practitioners and one physician’s assistant) at the free clinic. All participants were female with ages ranging from 32-55 years. The total years in advanced practice were 67, the average being almost ten years. The range of experience in advanced practice was from a minimum of two years to a maximum of 16 years. All seven participants answered the first two sets of surveys (pre and post 1). Five surveys were returned for the second set of post tests (post 2). Analyses

The Kruskal-Wallis, a non parametric analysis of variance (ANOVA) statistic, was utilized for the analysis of the attitudes and beliefs at the three time periods. The level of significance was set at $p<0.05$. The Pearson Chi-Square statistic was utilized to analyze the knowledge scores at the three time periods. The Chi-Square statistic was used to evaluate the results of the chart review, measuring differences in the frequency of the documentation of physical activity from period one (three months prior to the education session) to period two (three months after the education). Determining whether or not a specific plan was included in the discussion was another piece of information assessed from the chart review. The distribution of the promotional bags and the use of the green sheets were also tracked. 


\section{Attitudes and Beliefs Survey}

The attitude and belief survey contained fifteen items, which were assessed at three points in time pre, post 1 , post 2.These questions and significance levels are presented in Table 2 in Appendix G. As indicated in the table, there were no significant changes from baseline to either post test 1 or 2 among the items.

The next five items on the attitude scale measured the provider's belief in the importance of health promotion in general and about the importance of encouraging patients to engage in physical activity. The exact questions in their entirety are found in Table 2 in Appendix G. None of these items revealed any statistical significance which could lead one to conclude that the baseline attitudes and beliefs of the providers about physical activity promotion were fairly high. However, a statistically significant change was noted from the pre test to post 1 for the item "I have sufficient knowledge to advise patients about physical activity.” On the pre test, 42.9\% agreed or strongly agreed with the question. On post test 1, 100\% agreed or strongly agreed and this percentage was maintained on post test 2 . The conclusion may be drawn that knowledge was retained from the pre test to post 2.

Although the majority of the reported items on the attitudes and beliefs scale were not statistically significant, there were, however, some changes noted in attitudes and beliefs in the group, between the time periods. To the question "There is usually enough time during a routine appointment to discuss physical activity with my patients”, no one agreed that there was enough time at the pre test. At post test 1, 29\% agreed and at post test 2, 60\% agreed there was enough time. This shows a $60 \%$ overall increase in the belief that there is enough time for advice from the pre test to post test 2 . The perception then of having enough time to advise patients about 
physical activity during a routine appointment increased in a positive direction during the implementation period.

The item "I can provide useful tips to my patients on physical activity" showed an overall tendency towards significance $(p=.066)$. In the pretest, $29 \%$ strongly agreed with this statement while in post test $1,86 \%$ strongly agreed. This decreased slightly in post test 2 with $80 \%$ strongly agreeing.

Two items on the attitudes and beliefs survey addressed the topic of health promotion and the responses changed between the three survey times. Eighty-five percent in the pre test answered strongly agree compared to $100 \%$ that strongly agreed in post tests 1 and 2 with the statement "Health promotion is an important part of primary care.” Interestingly, to the statement "Promoting physical activity is important in primary care”, 86\% in the pre education session, and $100 \%$ strongly agreed immediately after the education session, but only $60 \%$ strongly agreed in post test 2. One could hypothesize that the effect of being together in a group and being enthusiastic about the new knowledge and the prospect of delivering health promotion to patients was diluted somewhat after time passed and when the providers were on their own. Perhaps they recognized the difficulty of incorporating this change into busy practices. Another explanation could be related to the absence of the group energy and support once the education session ended.

\section{Knowledge Survey}

A survey from the American College of Sports Medicine and the Centers for Disease Control (CDC) measuring knowledge of the current recommendations for physical activity was also administered at the three time periods. Chi-square analysis was used for the three points in time, to determine the number of right or wrong answers. The Kruskal-Wallis, a non parametric 
analysis of variance (ANOVA), was utilized for analysis of the knowledge scores. The level of significance was set at $\mathrm{p}<0.05$. Each of the 12 items was scored individually and then the total scores of the three groups of surveys were compared. Questions number one and fourteen were not included in the scoring. The first question "Have you heard about the national physical activity recommendation?” did not reflect knowledge. Question number 14 was designed to provide some of the answers and thus was deleted.

The overall knowledge pre test mean was 9.29, the post 1 mean was 11.86 , and the post 2 mean was 12.00 , showing that all participants had a perfect score on the final survey. This demonstrates that the knowledge was retained over the twelve week intervention period. The knowledge test statistics across the three time periods analyzed with the Kruskal Wallis test were significant at the .001 level.

\section{Qualitative Data}

Five of the seven participants provided open responses at the end of the project implementation period. The responses were as follows:

- The bright green color is a flag for me to discuss physical activity with patients. When it is not there, I tend to forget it is an issue.

- Patients really liked receiving gift bags and pedometers. It was good to not only tell a patient about something they needed, but also to provide it for them, eg. pedometer, water bottle, trail maps, etc... Having the clinic staff place worksheet on chart was a good prompt/cue to discuss exercise with pt. In-service was excellent and provided just the right amount of info we needed to get started. Changing behavior is extremely complex...the pts for the most part seem to want to change, but often are not able to make that leap from off the couch into 
action...Having these kits to offer as inspiration helped them to get started. Thanks for all your efforts!

- I loved the gift bag that we could provide to the pts! I think this was very motivating to them. Also the handouts and pamphlets are very useful. Not being able to give patients with an e-chart the information hindered my participation as a lot of my patients have e-charts. Very well organized! Excellent project.

- Helpful to remind me to discuss exercise at each visit. The green sheet is the best reminder. It is bright and catches your eye as you grab a chart and move on. Especially helpful on busy days to remind that health is also a part of every visit, not just annual.

- This project has pushed preventive medicine to the front of my mind during my pt. exams. I am more aware and concerned about my patient's activity level. Each patient that I talked with about this study was receptive and eager to try the pedometer. The downside was the study time was too short. I only had one repeat visit with a patient that I recall.

An overriding theme found in the open ended responses was that prompts and reminders are very helpful and necessary to bring the topic to the forefront of the mind of the provider. It may be that providing prompts is a vital component when introducing a practice change. Another common theme was that having the promotional items was helpful to assist in the discussion.

Chart Review

The review of 200 charts took place at the end of the twelve week project implementation period. One hundred charts were randomly selected for the period of time three months prior to 
the project start date (January-March, 2009). The sample command in the statistical software called R was used for the list of random numbers. An additional 100 charts were randomly selected for review for the months after the project implementation period (April-June, 2009). Only the patient encounters of the seven regular providers were chosen. A total of 919 patient interactions with the seven providers, 428 in group 1, and 491 in group 2, took place during the time periods reviewed.

The primary objective for reviewing charts was to ascertain changes in the frequency of the provider's discussion of physical activity with patients. Additional information gathered from the chart reviews included age, gender, commonly encountered diagnoses, and body mass index (BMI) data. The frequencies for the diagnoses are depicted in Figure 1. The BMI ranges are depicted in Figure 2. Only the first 100 charts were reviewed for these items since there could have been repeat encounters of the same patients in the second group.

Demographics, Diagnoses, and BMI

The mean age of the 100 patients was 48.80 years. The ages ranged from 21 years to 68 years. Seventy-eight percent were female and $22 \%$ were male. The most frequent diagnosis in the chart review was hypertension (56\%). Dyslipidemia at 43\% was the second most common. Gastro esophageal reflux disease (GERD) was the third most common at 35\%. The frequency of type 2 diabetes was 31\%, and 30\% of the sample had a documented diagnosis of depression. Twenty-three percent of the patients reviewed had a diagnosis of obesity. See Figure 1 for the prevalence of documented diagnoses in the free clinic.

The scale for the BMI ranges is from the National Heart Lung and Blood Institute, a division of the Centers for Disease Control and is as follows: Underweight $<18.5$, Normal Weight $>=18.5$ and $<25$, Overweight $>=25$ and $<30$, Obese $>=30$ and $<40$, and Morbid Obesity 
$>=40$. The BMI results from the chart review were $2 \%$ underweight, $11 \%$ normal weight, $15 \%$ overweight, $41 \%$ obese, with $31 \%$ in the morbidly obese range. The average BMI of the patients in the first 100 charts reviewed was 35. The range of BMI's was 15.2 to 61.8. See Figure 2 for the BMI frequencies.

\section{Documentation of Discussion of Physical Activity}

The 200 charts were reviewed to determine if a change was made in the discussion of physical activity from period 1, three months prior to the project implementation, to period 2, three months after the initiation of the project. This was the primary objective. The overall discussion of physical activity was examined and the documentation of a plan was analyzed. Chi-square statistics were used to evaluate differences in the frequency of physical activity documentation from period 1 to period 2.

The discussion of physical activity increased two fold from $16 \%$ to $32 \%$. The discussion took place 16 times in the first 100 charts reviewed and 32 times in the second set of 100 charts. There was a significant overall increase in the discussion of physical activity in general. Using the Pearson Chi-square statistic this was significant at the .008 level, meaning there was a significant change from before the education to after the education took place.

Specific plans to increase activity and plans for follow up were monitored. The distribution of the green sheets was tracked for the application of the 5 A's. In the random sample of the 100 charts after the education took place, 11 green sheets utilizing all of the 5 A's including a documented plan were used and they included a documented plan. Because of the random sampling design, the true number of green sheets was not reflected. The staff kept a tally of the number of green sheets used and the total was 56. Therefore, 45 green sheets were used in addition to the 11 found in the sampling of charts. 
Among the charts in which physical activity was discussed, six of the sixteen in period one identified a plan, while in period 2, 23 of the 32 identified a plan. Using the Pearson Chisquare statistic, this represented a significant difference at the .02 level. Some of the comments on the green sheets included plans to begin walking or to increase the number of times currently walking weekly. One provider discussed the use of exercise as a distraction or trigger relief while the patient was stopping smoking. Another discussion on the green sheet included asking a husband and wife what activities that they enjoyed together. Lastly, 65 of the 75 promotional bags were distributed during the twelve week implementation period. The remaining ten bags have been distributed since then.

\section{Discussion}

The purpose of this project was to initiate a practice change to increase the promotion of physical activity with patients. Education influenced the perception of having sufficient knowledge to advise patients about physical activity. Additionally the belief that there is enough time in a routine visit to discuss the topic improved from the pre test to the post test 1 and 2. Improving knowledge and attitudes is supported in the literature by the 2004 study conducted by Douglas, et al., whereby it was recommended to improve the knowledge of the current guidelines for physical activity.

The use of the posters, pamphlets, and prompts are supported in the literature. According to the Douglas study, tools should be developed to support individual assessment and advice giving to suit individual circumstances. Barriers noted by providers in the Douglas study were lack of time and resources. The green sheets with the 5 A's were intended to be a resource (a tool) to aid in reducing the barrier of time involved in discussing physical activity. The 5 A's was also a tool useful for addressing individuals and for tailored plans. In the open ended responses, 
participants said that the green sheets were helpful as reminders. System prompts are one of the methods supported in the literature to enhance the success of health promotion topics, (Yancey, et al., 2006). The findings from the 2007 Kessler and Alverson study, indicate the need to include both visual and auditory health education initiatives, and that future research should focus on how to increase other underserved and uninsured clients' use of health education materials (Kessler \& Alverson, 2007)

The goal of reaching a discussion of physical activity in 30\% of patients was obtained according to the results of the 100 charts reviewed in time period 2 (the time period three months after the education session). It could be assumed that the green sheet system prompts were efficient instruments to assist in this change. It is found in the literature that providers agree that the topic of physical activity should be discussed but that they struggle with the most efficient and effective method (Schrop, et al., 2006). The clinical guideline "Behavioral Counseling in Primary Care to Promote Physical Activity: Recommendation and Rationale recommended training of clinicians and system supports, both of which were included in the design of this study (USPSTF, 2002).

The results of the chart review for diagnosis frequencies and BMI clearly supports the need for health promotion and the encouragement of physical activity. The top diagnoses were hypertension, dyslipidemia, diabetes, GERD, and depression, all diagnoses that could be helped by weight loss, increased activity, or both. The average BMI was 35 with $15 \%$ being overweight and $72 \%$ either obese or morbidly obese, yet only $23 \%$ had a documented diagnosis of obesity.

A 2006 West Virginia Behavioral Risk Factor Survey report lists hypertension (31\%) as the most frequent diagnosis in the state, which was far below the frequency of $51 \%$ in this sample (BRFSS, 2006). In the BRFSS report, obesity was reported in $31 \%$ of the West Virginia 
respondents compared to the U.S. rate of $26.3 \%$ (BRFSS, 2008) and the sample rate of 23\%. It is possible that obesity was under documented in the MPHR sample. According to the BRFSS data, the prevalence of diabetes was $12 \%$ in the state compared to a prevalence of $8 \%$ in the United States. The prevalence of diabetes in this sample was 31\%.

In relation to the change in the system that this project involved, Roger's Diffusion of Innovations Theory was used successfully as a guide for the development of this project. Stage Theory as it is known, is based on the idea that organizations pass through a series of steps or stages as they change. These steps or stages are as follows: problem definition (awareness), initiation of action (adoption), implementation, and institutionalization (Rogers, 2003). Problem definition or awareness was developed through the literature review, the discussions with the stake holders, including the director of the free clinic, and through the education session. The initiation of action and implementation took place during the twelve weeks after the education session. During this stage, reactions and role changes occur. Reactions were compiled with the request for open ended responses. Informal reactions were noted when the project director was in the clinic during which time discussions took place about the helpfulness of the green sheets and the promotional bags. Role changes occurred as the providers attempted to add the components of the project to their customary patient encounters.

This theory falls under the broad category of organizational change. Organizational change is best promoted at multiple levels within an organization. The stages signal when to involve organization members and decision makers at various points in the change process (Rogers, 2003). All members of the organization were aware of or involved either directly or indirectly with this project. Institutionalization and entrenchment have not taken place. There are plans to include electronic prompts in the e-charts which will enhance institutionalization. 
Additionally, the clinic staff seems to be in interested in moving in the direction of health promotion and risk reduction, as evidenced by the wellness participatory planning program and by the grant that has been secured for a health educator.

The literature supports a united approach to health promotion and therefore an organizational theory such at the Theory of Innovations is fitting. The effective strategies to address this problem should involve a united approach and engage all staff and community partners, not just the clinicians, for health behavior changes to be optimized (Flocke, Crabtree, \& Stange, 2007).

\section{Strengths and Weaknesses}

There were several facilitators of the project. First, the director, clinic staff, and providers were supportive of the project. The timing seemed to be ripe for health promotion projects. The director has a personal and professional interest in health promotion and had secured a grant to hire a health educator, whose main purpose was to educate and assist patients with health promoting behaviors, addressing such problems as obesity and physical inactivity. Also, at the same time as the project was being implemented, a steering committee was developed for the purpose of participatory planning to help identify and develop wellness resources for the clinic. Having these events coincide helped to foster the initiation of the development of a system wide change and to elevate the clinic environment to one of health promotion and risk reduction, not just disease treatment. An additional strength was that the project was developed based on a review of the literature and the interventions used to influence provider practice were aimed at reducing barriers.

Another fortuitous occurrence for this project was the acquisition of grant funding from the American Academy of Nurse Practitioners and from the Dean's fund for DNP projects. 
These funds were used for the promotional bags, the posters, a physical activity DVD for the waiting area, and to provide lunch for the participants during the noon hour education session.

The project timeline proved to be a moving target. The original plan was for the project to be completed by April or May of 2009. One of the unanticipated major delays was that it took from November 2008 until February 2009 to receive approval from the IRB. Eventually, nine versions of the IRB application were submitted by the project director and the committee chair.

Several limitations may have impacted the effect of the practice change project. First, the project director was not available to be present in the clinic on a daily basis, to serve as a constant change agent. Another obvious limitation was the small number of participants. Also, only one of the participants practiced on a full time basis. The impact of the differences between full time and part time providers is unknown, but it warrants mentioning.

The requirement of additional time burdens put on the providers was another area of weakness. Although, efforts were made to lessen this burden through the use of a checklist, time is limited and anything that requires more time per patient encounter may be difficult to sustain.

Unfortunately, this project was being designed at the time of the clinic's transition from paper records, to an electronic medical record system. Based on the assumption that adding the project to the electronic record, while providers were on the upward slope of the learning curve, and that this would place undue stress and strain on them, influenced the decision to conduct the project with paper charts only. It was unknown at the time just how long that it would take for providers to be comfortable with the new system. During the implementation period, the number of electronic charts was expanding and they were not able to be included in the project because of the design. In retrospect, this was a design flaw, because it seemed to add confusion to the process. 
Another limitation is that perhaps more specific and useful information would have been elicited from the open ended responses if direct questions were asked. A question such as "What might encourage you to advise patients about physical activity?” could have garnered better information. Finally, an obvious limitation was that no patient outcomes were tracked.

\section{Recommendations}

Several recommendations can be made to promote this practice change for continuation and future expansion. Because physical inactivity is a public health issue in West Virginia, and because the cost of maintaining the project is minimal, it should be continued. It is recommended that the information on the green sheets be added to the electronic medical record and that a system prompt be developed. An additional recommendation, enhancing the promotion of this project is to provide a bulletin board in the waiting area and perhaps another in the provider's area that would be for the purpose of information about resources for increasing activity levels. It was beyond the scope of this project to track patient outcomes. A future recommendation is to include the patient outcomes associated with the pedometers.

While the response to the promotional items was very positive, this is not something that is necessarily sustainable. It is feasible that finances could be secured through a grant for more items of this nature, but it cannot be included in the future recommendations in light of cost constraints. Although the key players were the providers, an additional recommendation to enhance sustainability is to solicit change champions not only from within the organization but from the community as well. Participation is more likely to be sustainable with assistance from multiple levels.

This project has application in other free clinic settings. It is feasible to present the education session and the results at one of the West Virginia Free Clinic Association meetings 
and to make recommendations that it be added to the electronic medical record (EMR) system. This system is in place in many of the free clinics and also in some of the Federally Qualified Health Care Centers (FHQC). An additional viable option might be to conduct focus groups with the providers and staff of several clinics. The purpose of these focus groups would be to elicit perceptions about barriers and facilitators that influence the assessment and promotion of physical activity.

This project was congruent with the mission of the free clinic. The organization is committed to minimizing barriers to health care and providing quality comprehensive health care to the state's uninsured and working poor families. Promoting health through direct services, education, and advocacy are the primary goals. Educating the providers, staff, and patients about physical activity was in line with these goals, and offered health promotion resources for the patients and providers. If successful, this program has a direct impact on the quality of life of its patients, parallels with the goal of patient advocacy, and is part of a comprehensive plan of care. Changing behavior is complex whether it is the behavior of the providers or the patients. Changing the behavior of a system occurs at multiple levels. A unified approach is necessary to impact change in systems. Policy makers, practitioners, researchers, patients, and community members should partner so that the physically active lifestyle choices become the easier choices (Yancey, Ory \& Davis, 2006). The project was in congruence with the mission of the free clinic to provide quality, comprehensive care to the state's uninsured. The MPHR clinic can illustrate its commitment to the mission by continuing the practice change. Ultimately this practice change may result in improved health for the population served by the free clinic. 
Figure 1

Diagnosis Frequencies

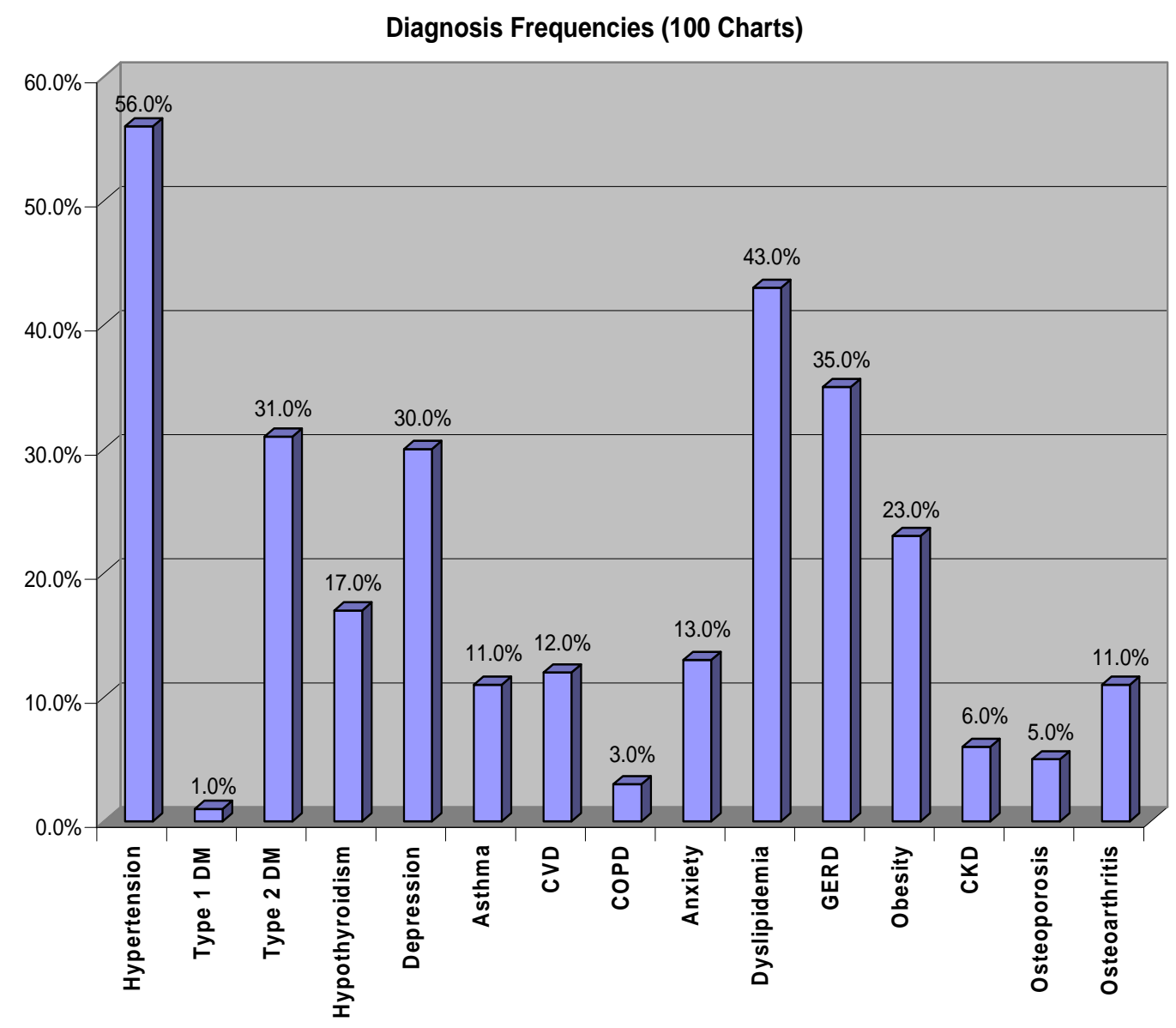


Figure 2

\section{BMI Ranges}

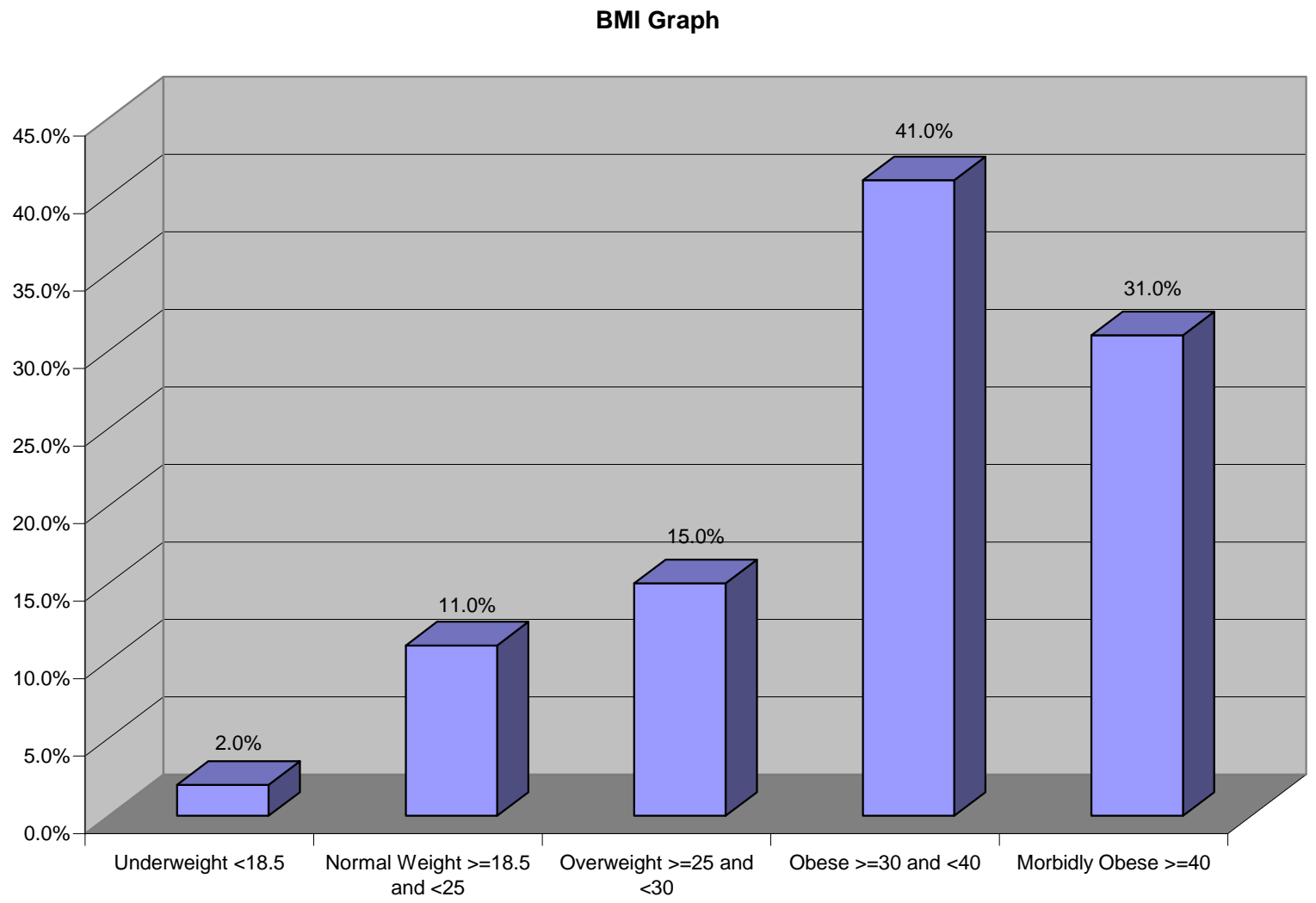




\section{References}

AHRQ (2005). National Health Care Quality Report. Available online at http://www.ahrq.gov/qual/nhqr05/nhqr05.pdf, last accessed 3/27/2008.

Aittasalo, M., Miilunpalo, D., Kukkonen-Harjula, D. \& Pasanen, M. (2006). A randomized intervention of physical activity promotion and patient self-monitoring in primary health care. Preventive Medicine, 42 (1), 40-46.

Behavioral Risk Factor Surveillance System (BRFSS), Prevalence Data (2008). Overweight and Obesity (BMI)-2007. Retrieved February 26, 2008, from http://www.cdc.gov/nccdphp/dnpa/obesity/economic_consequences.htm

Bellas, P., Asch, S., Wilkes, M. (2000). What students bring to medical school: Attitudes toward health promotion and prevention. American Journal of Preventive Medicine, 18, 242-248.

Blair, S., Kohl, H., Paffenbarger, R., Clark, D., Cooper, K., \& Gibbons, L. (1989). Physical fitness and all-cause mortality: A prospective study of healthy men and women. Journal Of The American Medical Association, 3;262 (17), 2395-2401.

Blair, S. \& Powell, K. (1994). The public health burdens of sedentary living habits: Theoretical but realistic estimates. Medicine And Science In Sports Exercise, 26 (7), 851-856.

Braveman, P. (2008). Robert Wood Johnson Foundation. Commission to Build a Healthier America. Robert Wood Johnson Foundation Launches Commission to Look Beyond Medical Care System to Improve the Health of All Americans. (n.d.). Retrieved March 25, 2008 from http://www.rwjf.org/pr/product.jsp?id=26672\&topicid 
Burton N., Oldenburg, B., \& Turrell G. (2003). Why socio-economic groups differ in their participation in leisure time physical activity. Health Education and Behavior, 30(2), 225-244.

Carroll, J., Fiscella, K., Meldrum, S., Williams, G., Christopher, N., Sciamanna, C., et al. (2008). Clinician-patient communication about physical activity in an underserved population. Journal of American Board of Family Medicine, 21, 118-127.

Colditz, G. (1999). Economic costs of obesity and inactivity. Medical Science and Sports Exercise, 31(11), 663-667.

Coyne, C., Demian-Popescu, C., \& Friend, D. (2006). Social and cultural factors influencing health in southern West Virginia: A qualitative study. Preventing Chronic Disease: Public Health Research, Practice, and Policy, 3(4), 1-7.

Douglas, F., Torrance, N., van Teijingen, E., Meloni, S., Kerr, A. (2006). Primary care staff's views and experiences related to routinely advising patients about physical activity. A questionnaire survey. BMC Public Health, 6, 138-148.

Ducatman, A., Vanderploeg, J., Johnson, M., Rubin, J., Harber, P., Sokas, R., et al., (2005). Residency training in preventive medicine: Challenges and opportunities. American Journal of Preventive Medicine, 28, 403-412.

Flocke, S., Crabtree, B., \& Stange, K. (2007). Clinical reflections on promotion of healthy behaviors in primary care practice. Health Policy, 84, 277-284.

Glasgow, R., Emont, S., \& Miller, D. (2006). Assessing delivery of the five 'As’ for patientcentered counseling. Health Promotion International, 21 (3), 245-255.

Hillsdon M., Foster C., Thorogood M. (2005). Interventions for promoting physical activity. (Cochrane Review) In: The Cochrane Library, Issue 1, 1-55. John Wiley \& Sons Ltd. 
Institute for Health and Clinical Excellence (2006). Four commonly used methods to increase physical activity. Available through the National Guidelines Clearing House, http://www.guideline.gov/ last accessed 3/10/2008.

Kessler, T. \& Alverson, E. (2007). Evaluating the effect of teaching modules on underserved clients’ perceived health. Research and Theory for Nursing Practice, 21, 98-208.

Marcus, B., Lewis, B., Williams, D., Dunsiger, S., Jakicic, J., \& Whiteley, J., et al. (2007). A comparison of Internet and print-based physical activity interventions. Arch Intern Med, 167(9), 944-949.

Marshall, A., Bauman, A., Owen, N., Booth, M., Crawford, D., \& Marcus, B. (2004).

Reaching out to promote physical activity: A statewide randomized controlled trial of a stage-targeted intervention. American Journal of Health Promotion, 18(4), 283-287.

Merom, D., Rissel, C., Phongsavan, P., Smith, B., Van Kemenade, C., Brown, W., \& Bauman, A. (2007). Promoting walking with pedometers in the community: the step-by-step trial. American Journal of Preventive Medicine. 3, 290-297.

Mokdad, A., Marks, J., Stroup, D., \& Gerberding. (2004). Actual Causes of Death in the United States. Journal of the American Medical Association, 291, 1238-1245.

National Institute for Health and Clinical Excellence (2006). Four commonly used methods to increase physical activity. Available through the National Guidelines Clearing House, http://www.guideline.gov/ Accessed November, 2007.

Reeve, K., Byrd, T., Quill, B. (2004). Health promotion attitudes and practices of Texas nurse practitioners. Journal of the American Academy of Nurse Practitioners, 16, 125-133.

Rogers, E. (2003). Diffusion of innovations ( $5^{\text {th }}$ ed). New York: Free Press. 
Ruelaz, A., Diefenbach, P., Simon, B., Lanto, A., Arterburn, D., \& Shekelle, P. (2007).

Perceived barriers to weight management in primary care-perspectives of patients and providers. Society of General Internal Medicine, 22, 518-522.

Schrop, L., Pendleton, B., McCord, G., Gil, K., Stockton, L., McNatt, J., \& Gilchrist, V. (2006). The medically underserved: Who is likely to exercise and why? Journal of Health Care for the Poor and Underserved, 17, 276-289.

Shepich, J., Slowiak, J., \& Keniston, A. (2007). Do subsidization and monitoring enhance adherence to prescribed exercise? American Journal of Health Promotion, 22(1), 2-5.

Sherman, B. J., Gilliland, G., Speckman, J. L., \& Freund, K. M. (2007). The effect of a primary care exercise intervention for rural women. Preventive Medicine, 44(3), 198-201.

Speck, B., Hines-Martin, V., Stetson, B., \& Looney, S. (2007). An environmental intervention aimed at increasing physical activity levels in low-income women. Journal of Cardiovascular Nursing, 22(4), 263-271.

United States Department of Health and Human Services (2000). Office of Disease Prevention and Health Promotion. Healthy People 2010. Retrieved March 3, 2008, from the World Wide Web: http://www.health.gov/healthypeople/

USPTF (2002). Behavioral counseling in primary care to promote physical activity: recommendation and rationale. Available through the National Guidelines Clearing House, http://www.guideline.gov/ Accessed November 2007.

West Virginia Bureau of Public Health. Access to Quality Health Service (2001). Available at http://www.wvdhhr.org/bph/hp2010/objective/1.htm, Accessed March 22, 2008.

West Virginia Department of Health and Human Resources. West Virginia Health Statistic Center (HSC), 2005, http://www.wvdhhr.org, Accessed April 11, 2008. 
West Virginia Geography from NETSTATE (2007). Available at http://www.netstate.com/states/geography/wv_geography.htm, last accessed 3/16/2008.

W.K. Kellogg Foundation (2004). [Electronic Version] W.K. Kellogg Foundation Logic Model Development Guide. Retrieved January 14, 2008 from htt://www.wkkf.org/Pubs/Tools/Evaluation/Pub3669.pdf

WV BRFSS 2004-2005 Report. Available at http://apps.nccd.cdc.gov/brfss/display.asp?yr=2005\&cat=EX\&qkey=4347\&state=WV, last accessed 2/6/2008.

Woolf, S., Glasgow, R., Krist, A., Bartz, C., Flocke, S., \& Holtrop (2005). Putting it together: Finding success in behavior change through integration of services. Annals of Family Medicine, 3 (2), 20-27.

World Health Organization (2003). WHO/Physical Inactivity: A Global Public Health Problem. Retrieved March 26, 2008 from http://www.who.int/dietphysicalactivity/factsheet_inactivity/

Wormald, H., Waters, H., Sleap, M., Bremer, L., (2006). Participants’ perceptions of a lifestyle approach to promoting physical activity: Targeting deprived communities in KingstonUpon-Hull. BMC Public Health, 6:202.Retrieved April 10, 2008, from BioMed Central. Yancey, A., Ory, S., \& Davis, S. (2006). Dissemination of physical activity promotion interventions in underserved populations. American Journal of Preventive Medicine,31 (4S), S82-S91. 


\section{Appendix A}

\section{Timeline}
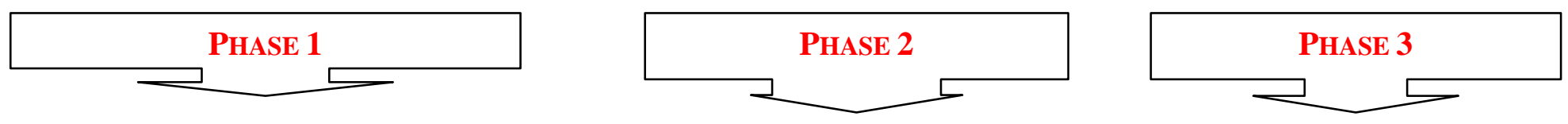

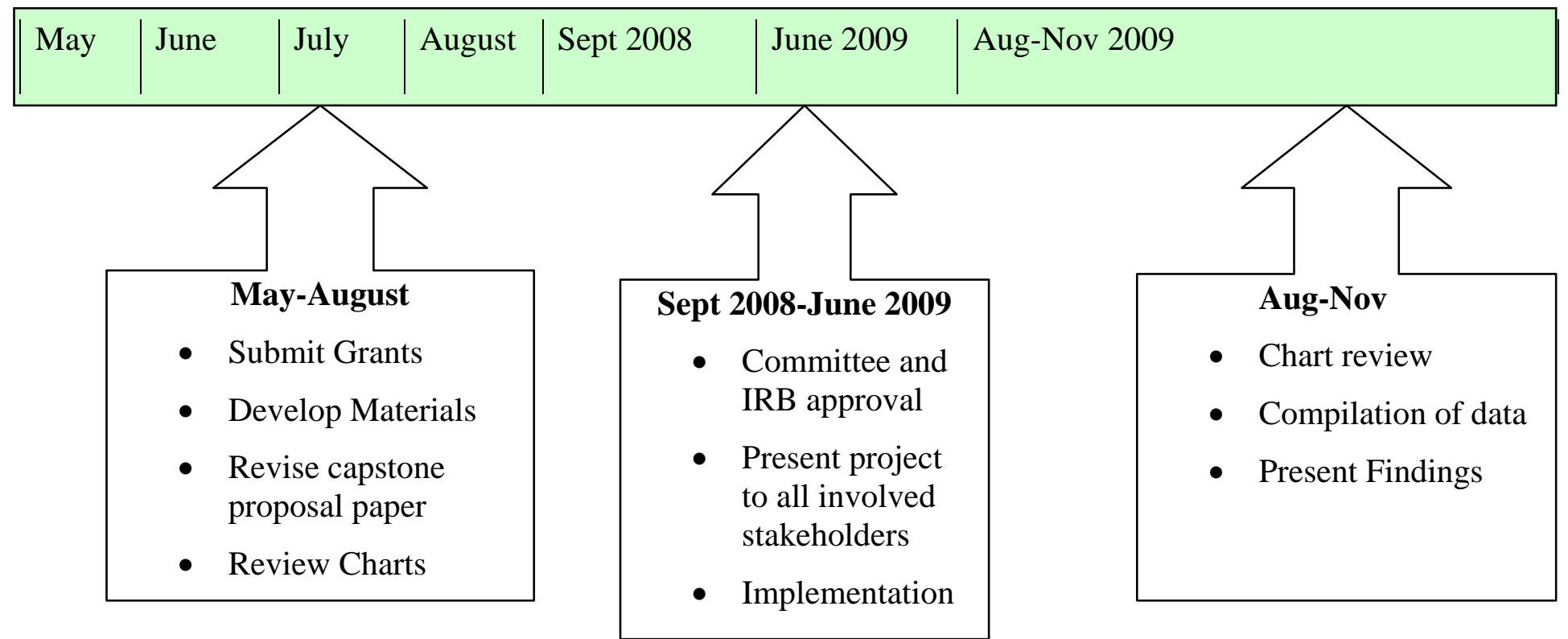




\title{
Appendix B
}

\author{
Milan Puskar Health Right, Inc. \\ 341 Spruce Street \\ Post Office Box 1519 \\ Morgantown West Virginia, 26507-1519
}

May 29, 2008

Dr. Susan McCrone, PhD, Professor

WVU School of Nursing

PO Box 9630

Morgantown, WV 26506

Dear Dr. McCrone,

This letter is to support Martha Summer's Capstone Project for her Doctor of Nursing Practice (DNP) degree. It is challenging for providers to consistently address health promotion topics, particularly physical activity, with patients. Martha has suggested a project that will assist providers with a practical and succinct method to assess and promote physical activity on a routine basis.

The Milan Puskar Health Right Clinic will be happy to provide space, time, and other similar support necessary to accomplish this project. We will gladly support this project and feel that if shown to be effective, it could positively impact patient care and outcomes.

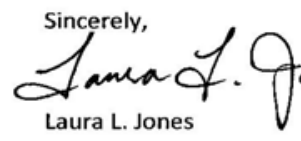

Executive Director, Milan Puskar Health Right 
Appendix C

\section{Physical Activity Survey}

For the following statements please answer according to the scale below: Thank you.

\begin{tabular}{|c|c|c|c|c|}
\hline $\begin{array}{l}\text { Strongly Agree } \\
1\end{array}$ & $\begin{array}{l}\text { Agree } \\
2\end{array}$ & $\begin{array}{l}\text { Neither Agree nor } \\
\text { Disagree } \\
3\end{array}$ & $\begin{array}{l}\text { Disagree } \\
4\end{array}$ & $\begin{array}{l}\text { Strongly Disagree } \\
5\end{array}$ \\
\hline
\end{tabular}

1. I _ I feel comfortable talking to my patients about physical activity

2. ___ There is usually enough time during a routine appointment to discuss physical activity with my patients

3. ___ I don't think talking to my patients about their activity levels would be helpful

4. ___ l can provide useful tips on physical activity to my patients

5. I I would like to be more involved in helping my patients manage their activity levels

6. People don't fit physical activity into their daily lives because it takes too much time

7. ___ People don't fit physical activity into their daily lives because it is too hard

8. ___ Sedentary patients should manage their activity on their own

9. Most sedentary patients have no motivation to begin a regular program of physical activity

10. I I only discuss physical activity if the patient mentions it

11. Health promotion is an important part of primary care

12. I _ only advise patients about physical activity if linked to their presenting problem

13. _ _ I try to encourage as many patients as possible to increase their physical activity

14. ___ Promoting physical activity is important in primary care

15. I _ I have sufficient knowledge to advise patients about physical activity 
The following questions are designed to assess knowledge about the recommendation for moderate physical activity from the American College of Sports Medicine (ACSM) and the Centers for Disease Control (CDC). Please answer to the best of your ability. If you do not know the answer to a question, please indicate that you do not know rather than leaving the question blank. Please check the appropriate box for each question. Thank you for completing this questionnaire.

1. Have you heard about the national moderate physical activity recommendation?

[ ] Yes

[ ] No

[ ] Don’t Know

Even if you have not heard of the national physical activity recommendation, please respond to the following questions because you may have heard information that could help you to answer these questions.

2. How many minutes per day of physical activity must an individual do to meet the national recommendation for moderate physical activity?

minutes per day

3. How many days per week does an individual need to do physical activity to meet the national recommendation for moderate physical activity?

days per week

4. Would physical activity performed for 5 minutes in the morning, 5 minutes in the afternoon, and 5 minutes in the evening be enough minutes of physical activity in a day to meet the national recommendations for moderate physical activity?

[ ] Yes

[ ] No

[ ] Don't Know

5. Would physical activity performed for 30 minutes in the morning be enough minutes of physical activity a day to meet the national recommendation for moderate physical activity?

[ ] Yes

[ ] No

[ ] Don’t Know 
6. Would physical activity performed for 10 minutes in the morning, 10 minutes in the afternoon, and 10 minutes in the evening be enough minutes of physical activity in a day to meet the national recommendation for physical activity?

[ ] Yes

[ ] No

[ ] Don’t Know

7. Would physical activity performed for 10 minutes in the morning and 10 minutes in the evening be enough minutes of physical activity in a day to meet the national recommendation for moderate physical activity?

[ ] Yes

[ ] No

[ ] Don’t Know

8. Would physical activity performed for 20 minutes in the morning, 10 minutes in the afternoon, and 10 minutes in the evening be enough minutes of physical activity in a day to meet the national recommendations?

[ ] Yes

[ ] No

[ ] Don't Know

9. Would physical activity performed on every day of the week be enough days of physical activity to meet the national recommendation for moderate physical activity?

[ ] Yes

[ ] No

[ ] Don't Know

10. Would physical activity performed on 6 out of 7 days a week be enough days of physical activity to meet the national recommendation for moderate physical activity?

[ ] Yes

[ ] No

[ ] Don’t Know

11. Would physical activity performed on 5 out of 7 days a week be enough days of physical activity to meet the national recommendation for moderate physical activity?

[ ] Yes

[ ] No

[ ] Don't Know

12. Would physical activity performed o 4 out of 7 days a week be enough days of physical activity to meet the national recommendation for moderate physical activity?

[ ] Yes

[ ] No

[ ] Don't Know 
13. Would physical activity performed on 3 out of 7 days a week be enough days of physical activity to meet the national recommendation for moderate physical activity?

[ ] Yes

[ ] No

[ ] Don't Know

14. Of the activities listed below, please check all that you believe are considered moderate physical activity according to the ACSM/CDC recommendation for moderate physical activity. (Note. Those with an asterisk are examples of moderate physical activity).

[ ] Mopping

[ ] Raking leaves

[ ] Using a sewing machine

[ ] Sitting, playing with children

[ ] Doing "aerobics" with a home video tape

[ ] Carrying a small child

[ ] Walking casually while pushing a stroller with a child

[ ] Walking with purpose (example: to catch the bus, get to work or class)

[ ] Actively playing with children outside

[ ] Mowing lawn using a push mower

[ ] Sweeping in the kitchen

[ ] Cooking

[ ] Dancing

[ ] Bathing the dog

[ ] Walking the dog

Thank you for completing this questionnaire! 
Appendix D

PHYSICAL ACTIVITY PROMOTION CHECKLIST

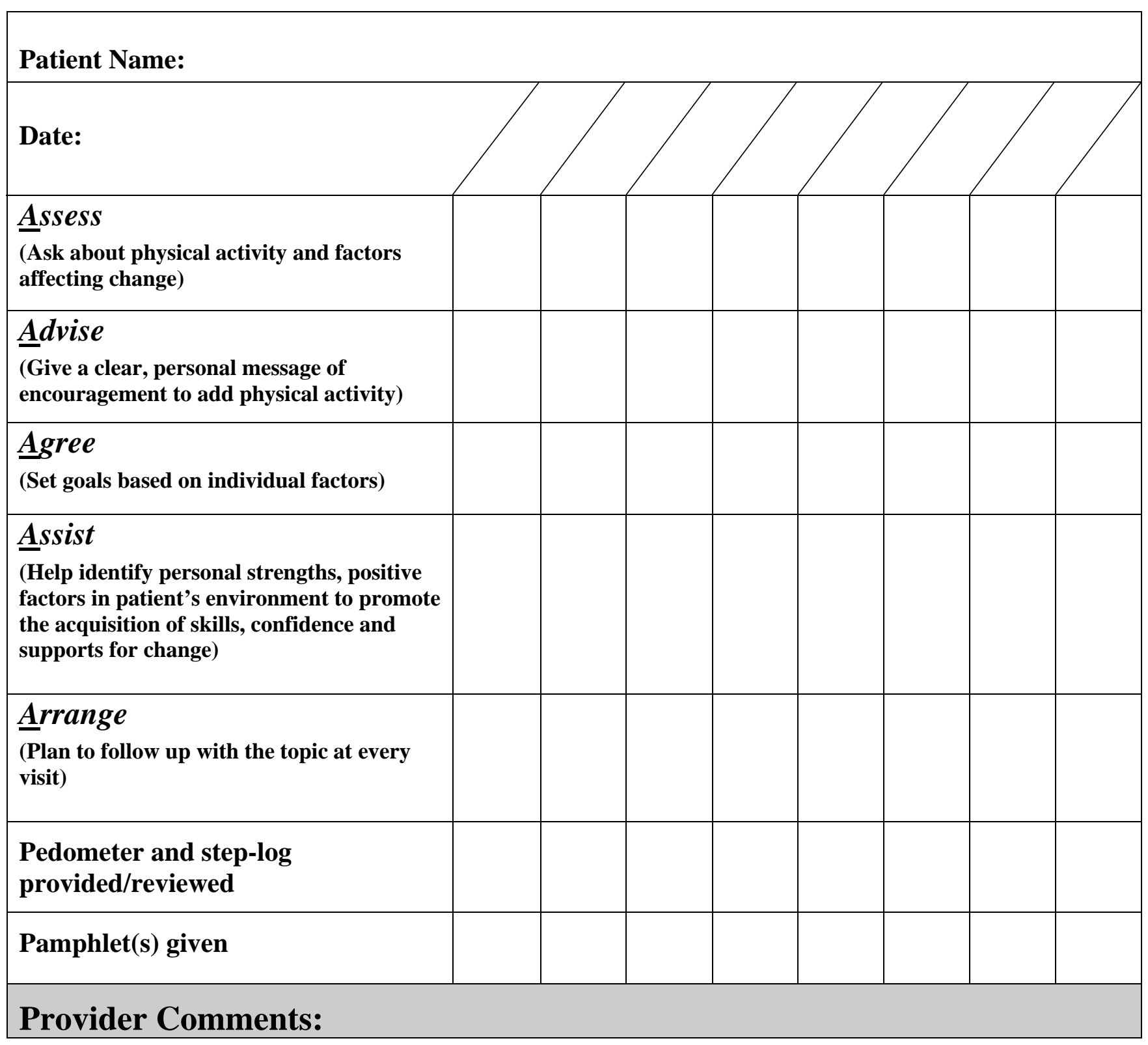

Provider Signature: 
Appendix E

Flow Sheet for Chart Review

1) Chart code (randomized number):

2) Patient Age:

3) Gender: F

M

4) Co-morbidities:

5) Discussion of Physical Activity: yes no

6) Key Words:

Walking:

Exercise:

Physical Activity:

Counseling/Discussion/Plan

Other? 
Appendix F

Table 1

Budget

Implementation cost Organization Cost

Estimated Return on

Investment

*Chart stickers. 2000 @ 180.00. None

The potential return on the

Available at printanything.com

investment is phenomenal if

*Posters.10 @ 10.95 ea = 109.50.

Available at

journeyworks.com

*Pedometers and step logs.150

@ 6.95 ea=1042.50 Available at

positivepromotions.com

*Pamphlets. Six titles promoting

physical activity.1200 total @

considering the cost of

inactivity to society and to the

clinic patients. Conditions that

could be eliminated or

ameliorated by physical

activity could potentially

decrease.

299.00

Display rack for pamphlets. 1 at

Better health for patients

59.00

Note:

potentially decreases the

Total expenses $=\$ 1690.00$

The clinic director has

overall burden on the clinic.

*Unaccounted grant funds will

obtained funding from other

be used for health promotion

sources for a television and

videos or DVD's for use in the

patient waiting area and

DVD player to be placed in

the waiting area.

additional materials as needed. 


\section{Appendix G}

Table 2

Test Statistics-Attitude and Beliefs

\begin{tabular}{|l|l|}
\hline Item & $p$ Value \\
\hline $\begin{array}{l}\text { I feel comfortable talking to my patients about physical } \\
\text { activity }\end{array}$ & .685 \\
\hline $\begin{array}{l}\text { There is usually enough time during a routine appointment } \\
\text { to discuss physical activity with my patients }\end{array}$ & .163 \\
\hline $\begin{array}{l}\text { I don't think talking to my patients about their activity } \\
\text { level would be helpful }\end{array}$ & .680 \\
\hline I can provide useful tips on physical activity to my patients & .066 \\
\hline $\begin{array}{l}\text { I would like to be more involved in helping my patients } \\
\text { manage their activity level }\end{array}$ & .424 \\
\hline $\begin{array}{l}\text { People don't fit physical activity into their daily lives } \\
\text { because it takes too much time }\end{array}$ & .890 \\
\hline $\begin{array}{l}\text { People don't fit physical activity into their daily lives } \\
\text { because it is too hard }\end{array}$ & .487 \\
\hline $\begin{array}{l}\text { Sedentary patients should manage their activity on their } \\
\text { own }\end{array}$ & .740 \\
\hline $\begin{array}{l}\text { Most sedentary patients have no motivation to begin a } \\
\text { regular program of physical activity }\end{array}$ & .345 \\
\hline I only discuss physical activity if the patient mentions it & .814 \\
\hline Health promotion is an important part of primary care & .424 \\
\hline $\begin{array}{l}\text { I only advise patients about physical activity if linked to } \\
\text { their presenting problem }\end{array}$ & .443 \\
\hline $\begin{array}{l}\text { I try to encourage as many patients as possible to increase } \\
\text { their physical activity }\end{array}$ & .798 \\
\hline Promoting physical activity is important in primary care \\
\hline $\begin{array}{l}\text { I have sufficient knowledge to advise patients about } \\
\text { physical activity }\end{array}$ & .514 \\
\hline
\end{tabular}

Chi-square

Level of significance $<0.05$

$* \leq .05$ 